1

2

3

\title{
Role of polyamines in plant growth regulation of Rht wheat mutants
}

Magda Pál ${ }^{1}$, Beti Ivanovska ${ }^{1}$, Tímea Oláh ${ }^{1}$, Judit Tajti ${ }^{1}$, Kamirán Áron Hamow ${ }^{1,5}$, Gabriella Szalai ${ }^{1}$, Radwan Khalil ${ }^{2}$, Radomira Vanková ${ }^{3}$, Petr Dobrev ${ }^{3}$, Svetlana P. Misheva ${ }^{4}$, and Tibor Janda $^{1}$

${ }^{1}$ Department of Plant Physiology, Agricultural Institute, Centre for Agricultural Research, Hungarian Academy of Sciences, 2462 Martonvásár, Hungary

${ }^{2}$ Botany Department, Faculty of Science, Benha University, Benha, 13518, Egypt

${ }^{3}$ Laboratory of Hormonal Regulations in Plants, Institute of Experimental Botany of the Academy of Sciences, 16502 Prague, Czech Republic

${ }^{4}$ Department of Plant Ecophysiology, Institute of Plant Physiology and Genetics, Bulgarian Academy of Sciences, 1113 Sofia, Bulgaria

${ }^{5}$ Plant Protection Institute, Centre for Agricultural Research of the Hungarian Academy of Sciences, Budapest, Hungary

*Corresponding author: Magda PÁL pal.magda@agrar.mta.hu

Tel: +36-22-569-502

Fax: +36-22-569-576 
Besides their protective role, polyamines also serve as signalling molecules. However, further studies are needed to elucidate the polyamine signalling pathways, especially to identify polyamine-regulated mechanisms and their connections with other regulatory molecules. Reduced height $(R h t)$ genes in wheat are often used in breeding programs to increase harvest index. Some of these genes are encoding DELLA proteins playing role in gibberellic acid signalling. The aim of the present paper was to reveal how the mutations in Rht gene modify the polyamine-regulated processes in wheat. Wild type and two Rht mutant genotypes (Rht 1: semidwarf; Rht 3: dwarf mutants) were treated with polyamines. Polyamine treatments differently influenced the polyamine metabolism, the plant growth parameters and certain hormone levels (salicylic acid and abscisic acid) in these genotypes. The observed distinct metabolism of Rht 3 may more likely reflect more intensive polyamine exodus from putrescine to spermidine and spermine, and the catabolism of the higher polyamines. The lower root to shoot translocation of putrescine can contribute to the regulation of polyamine pool, which in turn may be responsible for the observed lack of growth inhibition in Rht 3 after spermidine and spermine treatments. Lower accumulation of salicylic acid and abscisic acid, plant hormones usually linked with growth inhibition, in leaves may also be responsible for the diminished negative effect of higher polyamines on the shoot growth parameters observed in Rht 3. These results provide an insight into the role of polyamines in plant growth regulation based on the investigation of gibberellininsensitive Rht mutants.

Abbreviations: ABA: abscisic acid; ADC: arginine decarboxylase; APX: ascorbate peroxidase; CS: chorismate synthase enzyme; DAP: 1,3-diaminopropane; GAs: gibberellins; G-POD: guaiacol peroxidase; GR: glutathione reductase; IAA: indole-3-acetic acid; MDA: 
malondialdehyde; NCED: 9-cis-epoxycarotenoid dioxygenase; ODC: ornithine decarboxylase; PA: phaseic acid; PUT: putrescine; SA: salicylic acid; SPD: spermidine; SPDS: spermidine synthase; SPM: spermine. $t$-CA: trans-cinnamic acid. 


\section{Introduction}

Polyamines are aliphatic amines, which are found in all living cells. The most abundant polyamines in plants are putrescine (PUT), spermidine (SPD) and spermine (SPM), but the total and individual polyamine contents vary depending both on the plant species or organ and on the developmental stage. In addition, their metabolism is dynamic, as they can be rapidly converted into each other in the polyamine cycle (Pál et al., 2015). Besides their direct protective role, polyamines also regulate various cellular processes as signalling molecules suggesting that abiotic stress tolerance is predominantly influenced by the role of polyamines in signalling processes rather than by their accumulation. Most abiotic stress responses share common elements in their pathways, which are potential nodes for cross-talk of signalling molecules. Several of these common elements may serve as major switching points and have a role in stress tolerance. It is becoming more and more clear that polyamines are also switching points of this kind and that polyamine-induced responses are interconnected at many levels. Polyamines are involved in direct interactions with other metabolic routes and hormonal cross-talk, activating also the expression of stress-responsive genes (Alcázar et al., 2010). Microarray analysis of arginine decarboxylase $(A D C 2$ : the gene encoding one of the two enzymes responsible for PUT synthesis) overproducing Arabidopsis plants revealed both the up- and down-regulation of various stress-responsive, hormone- and signalling-related genes. These included genes encoding transcription factors and genes involved in the biosynthesis of abscisic acid (ABA), auxin, gibberellins (GAs) and salicylic acid (SA) (Marco et al., 2011). In transgenic Arabidopsis plants overexpressing spermidine synthase $(S P D S)$, genes involved in the biosynthesis of jasmonic acid and ABA, jasmonic acid- and SA-responsive genes or the genes of several transcriptional factors are also influenced (Marco et al., 2011). The relationship between polyamines and SA (Németh 
et al., 2002; Szepesi et al., 2011; Szalai et al., 2017) or ABA (Alcázar et al., 2006; Gondor et al., 2016; Pál et al., 2018) have been studied in various plant species. However, little is known about the interaction between polyamines and GAs.

GAs are tetracyclic, diterpenoid carboxylic acids that regulate major aspects of plant growth and development, including seed dormancy breakdown, stem and root elongation or leaf expansion. Thus, mutant plants deficient in GAs exhibit dwarf phenotypes (Daviere and Achard, 2013). Early results also demonstrated that GA treatment increased ADC, but decreased ornithine decarboxylase (ODC: the gene encoding the other enzyme of PUT synthesis) gene expression. Parallel with these changes polyamine, especially PUT and SPD contents increased in red-light-induced etiolated Alaska pea epicotyls (Dai et al., 1982). GA 3 -induced increase in internode growth resulted from enhanced polyamine biosynthesis through the ADC pathway. Furthermore, the $\mathrm{GA}_{3}$-induced increase in $\mathrm{ADC}$ activity probably requires de novo synthesis of both RNA and protein (Kaur-Sawhney et al., 1986). GA application in barley seedlings also increased the level of free PUT in roots and leaf blades of Maythorpe (wild type) and Golden Promise (semi-dwarf mutant) cultivars, but the effect was greatest in leaves of cv. Maythorpe, suggesting that polyamines may play a role in GA-induced epicotyl and leaf-blade elongation in barley (Asthir et al., 2004). However, polyamines do not mediate the entire action of GA in pea internode growth (Smith et al., 1985).

$A D C 2$ overexpressing transgenic Arabidopsis plants exhibited a reduction in both the contents of $\mathrm{GA}_{1}, \mathrm{GA}_{4}$ and $\mathrm{GA}_{9}$, and the expression levels of the AtGA20ox1, AtGA3ox1 and AtGA3ox3 transcripts (Alcázar et al., 2005), which encode the two key enzymes in the terminal steps of GA biosynthesis, GA 20-oxidase (GA20ox) and GA 3-oxidase (GA3ox)(Hedden and Thomas, 2012). The accumulation of SPM in spermine synthase (SPMS) overexpressing 
Arabidopsis also correlated with the downregulation of GA 20-oxidases and GA 3-oxidase transcripts; in addition, GA catabolism was enhanced (Gonzalez et al., 2011). These findings suggest that polyamine accumulation represses GA accumulation. However, SPD and SPM treatment provided protection against drought stress in creeping bentgrass, which was accompanied with increased level of $\mathrm{GA}_{1}, \mathrm{GA}_{4}$, and $\mathrm{GA}_{20}$ compared to drought-treated ones (Krishnan and Merewitz, 2017).

GAs promote tissues expansion through the degradation of growth inhibitors known as DELLA proteins (Harberd et al., 2009). In wheat, DELLAs are products of the reduced-height genes $(R h t)$, and the mutations at the $R h t$ loci encode DELLAs that are unable to interact with the GA receptor. This GA-insensitive mutation results in a similar dwarf phenotype as those of GAdeficient mutants (Hoogendoorn et al., 1990). Recent studies showed that the wheat mutant line (Rht 3) carrying the severe dwarfing allele Rht-B1c was more tolerant to water deficiency than the tall isogenic line (Rht) with the wild Rht-B1a allele, due to its better activated antioxidant system, increased osmolyte accumulation and retained photosynthetic activity (Kocheva et al., 2014a; b; Nenova et al., 2014). Furthermore, this dwarf mutant was also more tolerant to cadmium stress (Dobrikova et al., 2017).

The aim of the present study has been to reveal the interaction between the mode of action of polyamines and GAs, when PUT, SPD and SPM were applied on wheat $R h t$ isogenic lines. Examining the effect of exogenous polyamine treatments, the changes in endogenous polyamine levels and related processes may reveal the polyamine-dependent regulatory mechanisms in plants. Higher polyamines were reported to have adverse effects on the growth of crop plants, depending on the plants species, and in relation to the polyamine metabolism and SA accumulation (Szalai et al., 2017). Thus, this study has been focused on elucidation how 
polyamine treatments influence i. plant growth, physiological status and endogenous polyamine metabolism; ii. the level of selected plant hormones in GA-insensitive wheat lines compared to the wild type. The obtained results may highlight the mode of action of polyamines in wheat lines with different $R h t$ alleles.

\section{Materials and methods}

\subsection{Plant materials, growth conditions and treatments}

Wheat (Triticum aestivum L.) variety 'April Bearded' near-isogenic lines (NILs) carrying the alleles Rht-B1b (semidwarf line: Rht 1), Rht-B1c (dwarf line: Rht 3) and the tall wild type (Rht) were used. The Rht 1 and Rht 3 lines were developed by Flintham et al. (1997), maintained at the seed gene bank of the Leibniz Institute of Plant Genetics and Crop Plant Research (IPK), Gatersleben, and multiplied in the experimental plots of the Institute of Plant Physiology and Genetics, Sofia. Seeds from one harvest season (2017) were used for two independent experiments.

The wheat seeds were germinated for 3 days at $26^{\circ} \mathrm{C}$, thereafter plants ( 15 seedlings/ plastic containers) were grown in modified Hoagland solution (Pál et al., 2005), which was changed every 2 days. Plants were placed in a randomized manner in a Conviron GB-48 plant growth chamber (Controlled Environments Ltd, Winnipeg, Canada) in the phytotron of the Agricultural Research Institute of the Hungarian Academy of Sciences at $22 / 20^{\circ} \mathrm{C}$ day/night temperature with 16/8-h light/dark regime. The photosynthetic photon flux density was $250 \mu \mathrm{mol}$ $\mathrm{m}^{-2} \mathrm{~s}^{-1}$, provided by metal halide lamps, with relative humidity of $75 \%$.

Based on the data from previous experiments (Szalai et al., 2017), $0.5 \mathrm{mM}$ concentration was chosen for the polyamine treatments. After 10 days of growth in Hoagland solution, the 
wheat seedlings were grown further under controlled growth conditions in hydroponic solution or were treated with $0.5 \mathrm{mM}$ PUT, SPD or SPM hydroponically in plastic containers. Samples were collected after 7-day treatments.

\subsection{Determination of growth parameters, proline content and lipid peroxidation}

The plant root and shoot length and the root and shoot fresh weight (FW) were followed. The proline content was determined according to the method of Bates et al. (1973). Briefly, the samples $(0.5 \mathrm{~g} \mathrm{FW})$ were homogenized with $5 \mathrm{ml}$ of distilled water. The extract was centrifuged at $10.000 \mathrm{rpm}$ for $10 \mathrm{~min}$ at $4{ }^{\circ} \mathrm{C}$. The supernatant $(1.7 \mathrm{ml})$ was mixed in a 1:1:1 ratio with ninhydrin acid and glacial acetic acid. The mixture was incubated at $100{ }^{\circ} \mathrm{C}$ for $1 \mathrm{~h}$. The reaction was arrested in an ice bath, the chromophore was extracted with $5 \mathrm{ml}$ toluene and its absorbance was determined at $520 \mathrm{~nm}$ using a UV-Visible spectrophotometer (160A, Shimadzu Corp, Kyoto, Japan).

The lipid peroxidation analysis was based on the malondialdehyde (MDA) determination. The tissues $(0.2 \mathrm{~g} \mathrm{FW})$ were ground in $900 \mu 10.1 \%(\mathrm{w} / \mathrm{v}) \mathrm{TCA}$, then centrifuged at $12.000 \mathrm{rpm}$ for $10 \mathrm{~min}$ at $4^{\circ} \mathrm{C} .450 \mu \mathrm{l}$ of the supernatant was mixed with $2 \mathrm{ml}$ of $0.5 \%(\mathrm{w} / \mathrm{v})$ TBA in $20 \%$ (w/v) TCA and incubated at $90{ }^{\circ} \mathrm{C}$ for $30 \mathrm{~min}$. The MDA concentration was measured spectrophotometrically at $532 \mathrm{~nm}$ (UV-Visible 160A spectrophotometer, Shimadzu Corp, Kyoto, Japan), with the subtraction of non-specific absorption at $600 \mathrm{~nm}$. MDA was then quantified using an extinction coefficient of $155 \mathrm{mM}^{-1} \mathrm{~cm}^{-1}$, and expressed as $\mathrm{nM} \mathrm{g} \mathrm{g}^{-1}$ fresh weight (Thomas et al., 2004).

\subsection{Antioxidant enzyme assays}


For the analysis of antioxidant enzyme activities, leaf and root tissues ( $0.5 \mathrm{~g} \mathrm{FW})$ were homogenized in $2.5 \mathrm{ml}$ ice-cold Tris buffer $\left(0.5 \mathrm{M}\right.$, pH 7.5) containing $3 \mathrm{mM} \mathrm{MgCl}_{2}$ and $1 \mathrm{mM}$ EDTA.

The ascorbate peroxidase (EC 1.11.1.11.) (APX) activity was determined in $0.2 \mathrm{M}$ Tris buffer ( $\mathrm{pH} 7.8$ ) and $5.625 \mathrm{mM}$ ascorbic acid. The reaction was started with $0.042 \% \mathrm{H}_{2} \mathrm{O}_{2}$ (Janda et al., 1999). The decrease in absorbance at $290 \mathrm{~nm}$ was monitored.

The guaiacol peroxidase (EC 1.11.1.7.) (G-POD) activity was measured at $470 \mathrm{~nm}$ as described by Ádám et al. (1995). The reaction mixture consisted of $88 \mathrm{mM}$ Na-acetate buffer (pH 5.5), $0.88 \mathrm{mM}$ guaiacol, $0.0375 \% \mathrm{H}_{2} \mathrm{O}_{2}$ and enzyme extract

The glutathione reductase (EC 1.6.4.2.) (GR) activity was determined at $412 \mathrm{~nm}$ according to Smith et al. (1988). The reaction mixture contained $75 \mathrm{mM}$ Na-phosphate buffer (pH 7.5), $0.15 \mathrm{mM}$ diethylenetriamine-pentaacetic acid, $0.75 \mathrm{mM} \mathrm{5,5'-dithiobis(2-nitrobenzoic}$ acid), $0.1 \mathrm{mM}$ NADPH, $0.5 \mathrm{mM}$ oxidized glutathione and $50 \mu \mathrm{l}$ plant extract in a total volume of $1 \mathrm{ml}$.

The enzyme activities were determined photometrically using UV-visible recording spectrophotometer (UV-VIS 160A, Shimadzu Corp. Kyoto, Japan). They were expressed in nkatal $\mathrm{g}^{-1} \mathrm{FW}$.

\subsection{Polyamine analysis}

Polyamine analysis was carried out as described by Németh et al. (2002). Leaf and root tissues $(200 \mathrm{mg})$ were homogenized with $2 \mathrm{ml} 0.2 \mathrm{M}$ ice-cold perchloric acid and allowed to stand for $20 \mathrm{~min}$ on ice. The extract was centrifuged at $10000 \mathrm{~g}$ for $10 \mathrm{~min}$ at $4{ }^{\circ} \mathrm{C}$ and the supernatant was used. For the pre-column derivatisation dansylchloride was used. $100 \mu 1$ of the 
supernatant was incubated with $200 \mu 1$ saturated sodium-carbonate and $400 \mu 1$ dansylchloride (50 $\mathrm{mg} \mathrm{ml}^{-1}$ acetone) at $60{ }^{\circ} \mathrm{C}$ and dark for $60 \mathrm{~min}$. The reaction was stopped with proline (100 $\mathrm{mg}$ $\mathrm{ml}^{-1}$ ). The most abundant polyamines, namely PUT, SPD and SPM together with DAP - the product of SPD and SPM terminal catabolism were analysed by HPLC using a W2690 separation module with $100 \times 2.1 \mathrm{~mm}$ Kinetex column $5 \mu \mathrm{m}$ (C18) (Phenomenex, Inc. Kalifornia, USA) and W474 scanning fluorescence detector with excitation at $340 \mathrm{~nm}$ and emission at $515 \mathrm{~nm}$ (Waters, Milford, MA, USA).

\subsection{Hormone extraction and analysis}

The extraction and chromatographic analyses were carried out according to Vrhovsek et al., 2012 with slight modifications. Plant samples were grinded using liquid nitrogen, then plant material (200 mg FW) was placed into $2 \mathrm{ml}$ Eppendorf tubes and $10 \mathrm{ng}$ of ortho-anisic acid was spiked from a solution of methanol:water $(1: 1 \mathrm{v} / \mathrm{v})$ in $1 \mu \mathrm{g} / \mathrm{ml}$ concentration as an internal standard prior to extraction. Then $1 \mathrm{ml}$ of methanol:water $(2: 1 \mathrm{v} / \mathrm{v})$ was added to the sample, which were vortexed vigorously for $1 \mathrm{~min}$, followed by 15 min shaking on a Bio RS-24 mini at maximum rotation. After centrifugation at $10000 \mathrm{~g}$ and $4^{\circ} \mathrm{C}$ for $5 \mathrm{~min}$, supernatants were collected, and the pellet was re-extracted with $1 \mathrm{ml}$ of methanol:water $(2: 1 \mathrm{v} / \mathrm{v})$ for $1 \mathrm{~min}$. After centrifugation both supernatants were pooled and filtered through a $0.45 \mu \mathrm{m}$ PTFE filter.

Ultra performance liquid chromatography was performed using Waters Acquity I class UPLC system (Milford, MA, USA). Separation was achieved on a Waters Acquity HSS T3 column $(1.8 \mu \mathrm{m}, 100 \mathrm{~mm} \times 2.1 \mathrm{~mm})$, kept at $40{ }^{\circ} \mathrm{C}$. Mobile phase A was water containing 0.1 v/v \% formic acid, while mobile phase B was acetonitrile containing $0.1 \mathrm{v} / \mathrm{v} \%$ formic acid. The

flow was $0.4 \mathrm{ml} \mathrm{min}{ }^{-1}$, and the gradient profile was as follows: $0 \mathrm{~min}$ : $5 \% \mathrm{~B}$; from 0 to $3 \mathrm{~min}$ : 
linear gradient to $20 \% \mathrm{~B}$; from 3 to $4.3 \mathrm{~min}$ : isocratic $20 \% \mathrm{~B}$; from 4.3 to 9 min: linear gradient to $45 \% \mathrm{~B}$; from 9 to $11 \mathrm{~min}$ : linear gradient to $100 \% \mathrm{~B}$; from 11 to $13 \mathrm{~min}$ : kept at $100 \% \mathrm{~B}$; from 13.01 to 15 min: equilibration to the initial conditions of $5 \% \mathrm{~B}$. The injection volume was $2.5 \mu 1$. Samples were kept at $8{ }^{\circ} \mathrm{C}$ during the analysis. Mass spectrometry detection was performed on a Waters Xevo TQXS (Milford, MA, USA) equipped with a Unispray Source (US) with the following parameters: impactor voltage was $2 \mathrm{kV}$ in both positive and negative modes; nebulizer gas: 7 bar; desolvation temperature: $550{ }^{\circ} \mathrm{C}$; ion source temperature: $150{ }^{\circ} \mathrm{C}$; cone gas flow: 250 $1 \mathrm{~h}^{-1}$; desolvation gas flow: $10001 \mathrm{~h}^{-1}$. For collision gas, argon (5.0 purity) was used with a gas flow of $0.15 \mathrm{ml} \mathrm{min}{ }^{-1}$. Unit resolution was applied to each quadrupole. Dwell time was automatically calculated by the software, however at least 20 points were taken from each peak MRM transitions. Where possible, at least three MRM transitions were used for data acquisition and the transition having the highest $\mathrm{S} / \mathrm{N}$ ratio was used for quantitation (Table 2). Data processing was done using Waters MassLynx 4.2 and TargetLynx software.

\subsection{Gene expression analysis}

Total RNA was extracted from fully developed leaf and root samples using TRI Reagent ${ }^{\circledR}$. The samples were treated with DNase I and cleaned with a Direct-zol ${ }^{\mathrm{TM}}$ RNA MiniPrep Kit (Zymo Research, Irvine, CA, USA) according to the manufacturer's instructions. cDNA was synthesized starting from $1 \mu \mathrm{g}$ of total RNA. Reverse transcription was carried out by using M-MLV Reverse Transcriptase (Promega Corporation, Madison, WI, USA). $1 \mu$ l of 2-fold diluted cDNA, gene-specific primers and housekeeping primers (Table 3), PCRBIO SyGreen Mix (PCR Biosystems, London, UK) and CFX96 Touch ${ }^{\mathrm{TM}}$ Real-Time PCR Detection System (Bio-Rad, Hercules, CA, USA) were used for quantitative real-time PCR reaction. In every case 
a melt curve analysis was performed to confirm the amplification of a single gene product. The relative gene expression values were determined with the $\Delta \Delta \mathrm{Ct}$ method (Livak and Schmittgen, 2001), which data were statistically evaluated using the standard deviation and $t$-test methods. Ct values were normalized by the $\mathrm{Ct}$ values of housekeeping gene Ta2291 encoding for an ADPribosylation factor, a recently proposed reference gene for normalize gene expression in wheat (Paolacci et al., 2009; Giménez et al., 2011; Wang et al., 2018). The gene expression value was set to 1 in control treatments (calibrator) for each genotype and all the other treatments were given as values relative to this. So every control treatment represents an individual calibrator in the case of each genotype. All reactions were performed in triplicate using 3 biological and 3 technical repetitions.

\subsection{Statistical analysis}

Three independent biological experiments were performed, and representative data are presented. The results are the means of at least 5 replicates for spectrophotometric and chromatographic determinations. The data were statistically evaluated using the standard deviation and $t$-test methods using Microsoft Excel.

\section{Results}

\subsection{Effects of the exogenous polyamine treatments on the polyamine contents in the leaves and roots}

The most abundant polyamine in the leaves of the control plants was SPD (Fig. 1A-D). PUT and SPD treatments slightly reduced the PUT level in the leaves of Rht 3. In contrast, SPD or SPM treatments increased the PUT level in the wild type Rht (Fig. 1A). The SPD content did not show remarkable changes after the treatments; however, its level was the lowest in Rht 3 
genotypes in all the treatments (Fig. 1B). In contrast to these, SPM level increased in the SPMtreated Rht and Rht 3 plants (Fig. 1C). The 1,3-diaminopropane (DAP) is the metabolic product of the terminal catabolism of SPD and SPM which is catalysed by polyamine oxidase. Upon excess of polyamines, plants try to maintain an optimal concentration and ratio of individual polyamines, e.g. by their oxidation to DAP. In the leaves, the levels of DAP were stongly increased in SPM-treated Rht1 and Rht 3 plants (Fig.1D). In the roots, PUT was the most dominant polyamine (Fig. 2A). The polyamine pattern in the case of DAP and SPM exhibited similar changes as those described in the leaves (Fig. 2C-D). In addition, the root PUT and SPD contents also increased, especially after SPM treatment, with the highest accumulation in Rht 3 plants (Fig. 2A-C).

\subsection{Effects of polyamine treatments on the biomass parameters, lipid peroxidation, proline content and antioxidant enzyme activities}

Significant differences were detected between the three genotypes in the biomass parameters, especially between the wild type and the dwarf genotype (Fig. 3A-D). Interestingly, positive effect of the PUT treatment the increase of the shoot weight could be detected, in the highest extent in the case of Rht 3. Lower, but also beneficial effect was found in Rht 3 after of SPD treatment, while negative effect of SPM was demonstrated by the relative changes in the biomass parameters expressed (in comparison with the corresponding controls value), especially for Rht and Rht 1 genotypes (Fig. 4.). Although higher polyamines (SPD and SPM) inhibited almost all the biomass parameters in Rht and Rht 1, the shoot length and weight values of SPMtreated Rht 3 were similar to those of the control Rht 3 . Results also showed that the roots are more sensitive to polyamine treatments than the shoots. 
Under control conditions there were no significant differences in the MDA levels between the genotypes. Interestingly, MDA content in the leaves decreased after all the polyamine treatments in Rht 3 compared to the control. In contrast, a slight increase in the MDA content was observed in the roots of Rht 1 after PUT or SPM treatments. The other differences were not statistically significant (Fig. 5A).

The SPM treatment induced a significant accumulation of proline in the leaves of all genotypes. In addition, the highest level of leaf proline content was detected in the SPM treated plants Rht 3 plants (Fig. 5B). Regarding the roots, similar tendency was found as in the leaves, namely, the most distinc changes were observed after SPM treatment. The highest elevation of proline content was detected in the Rht (wild genotype) plants, while the Rht 1 and Rht 3, which had slightly less amount of proline. Nonetheless, significant increase was also found in root proline level in Rht 1 plants treated with SPD. An interesting phenomenon was observed in the leaves of PUT-treated Rht 3 plants: the proline content decreased compared to controls (Fig. 5B).

The GR enzyme activity showed a slight, but statistically significant increase in the leaves of the Rht and Rht 1 types after SPD treatment, while the GR activity was slightly reduced after SPM treatment in Rht and Rht 3 plants (Fig. 6A). The GR activity increased in all the tested genotypes in the roots upon excess of SPD (Fig. 6B). In the roots of Rht 3 plants treated with SPM - in contrast to the situation observed in the leaves - the GR activity increased. The guaiacol peroxidase (G-POD) activity in the leaves and in the roots was often higher in the Rht 3 than in the wild type Rht line. However, it did not show remarkable change after the polyamine treatments (Fig. 6C-D) with the exception of negative PUT effect in the leaves and roots of Rht line, also SPD decreased G-POD activity in the Rht and Rht 3 leaves. The APX activity did not display any particular changes in the leaves, except of an increase in Rht 1 after SPM treatment 
(Fig. 6E). On the contrary, it showed a dramatic increase in the roots in the case of Rht 3 genotype after PUT and especially SPM treatments (Fig.6F).

\subsection{Effects polyamine treatments on salicylic acid, auxin and abscisic acid contents}

Changes in the contents of SA and its precursor, trans-cinnamic acid ( $t$-CA) showed that PUT and especially higher polyamines induce the accumulation of these phenolic compounds in the leaves of wild type, but not in the Rht 1 or Rht 3 lines (Fig. 7A and 7C). Polyamine treatments did not induce remarkable changes in the levels of indole-3-acetic acid (IAA), a predominant auxin, but the pattern of the IAA changes indicated, that its concentration is usually lower in the roots of Rht 3 line than in the wild type Rht (Fig. 8A-B). Similar tendency was observed for ABA, and its degradation product, phaseic acid (PA) in the leaves, as their levels were generally lower in the Rht 3 line compared to Rht. In addition, both ABA and PA contents in the leaves tended to increase after polyamine treatments (Fig. 9A and 9C).

\subsection{The effects polyamine treatments on gene expression levels}

No differences were observed in the transcript level of SPDS gene, which encodes the spermidine synthase enzyme, between the three isogenic lines under control conditions either in the leaves or roots (Fig. 10A-B). However, slight but statistically significant decrease in SPDS transcription was found in the Rht 3 leaves after SPD and SPM treatments, compared to the wild type (Fig. 10A). In the roots significant difference was observed only in the case of PUT treatment, between the Rht wild type and Rht 3 dwarf genotypes (Fig 10B).

The chorismate synthase enzyme (CS) is responsible for the synthesis of chorismate, the end product of the shikimate pathway, which than serves as the precursor of SA either via $t$-CA or isochorismate (Chen et al., 2009). Although gene expression level of CS in the Rht lines did 
not differ under control condition either in the leaves and roots, in the Rht 3 dwarf mutant significantly lower expression of it was found after polyamine treatments compared to the wild type, especially in the leaves (Fig. 11A-B).

The expression level of 9-cis-epoxycarotenoid dioxygenase (NCED), which encodes the key enzyme involved in ABA biosynthesis, was also similar in the three tested genotypes, both in leaves and roots (Fig. 12A-B). In the case of Rht, the highest NCED transcript level was detected after SPD treatment both in the leaves and roots (Fig. 12A-B). The Rht 1 genotypes did not show any remarkable differences, while the Rht 3 can be characterized by the lowest $N C E D$ expression level after polyamine treatments both in the leaves and roots (Fig. 12A-B).

\section{Discussion}

The levels of polyamines are well controlled in order to meet the requirements to cope with the ever-changing environment. Recently it became clear that although positive correlation exists in some cases between the levels of polyamines and stress tolerance, not only the depletion of polyamines, but also their extensive accumulation may be deleterious (Jiménez-Bremont et al., 2014; Szalai et al., 2017). However, polyamines play their roles in regulation of plant growth and development, as well as in plant stress responses in complex synergistic or antagonistic interactions with various plant hormones (Anwar et al., 2015). Although more and more studies have been published on elucidation of the relationship between polyamines and different plant hormones, such as ABA (Pál et al., 2018), SA (Takács et al., 2016), auxins and ethylene (Mendes et al., 2011) or brassinosteroids (Choudhary et al., 2012), there are only a few results concerning polyamines and GAs (Gonzalez et al., 2011; Kolotilin et al., 2011). 
Considering the results on the polyamine levels in the three Rht lines of wheat treated with polyamines, we can conclude that polyamine treatments affect in a complex way endogenous polyamine pool, not only increase the level of the polyamine which was applied. For example, SPD or SPM treatments elevate not only SPD or SPM content, but also the level of PUT in the roots. In fact, this is due to the homeostasis mechanisms, which try to set an optimum polyamine levels and ratio, partly by back-conversion of SPD and SPM to PUT through the PA cycle (Pál et al., 2015). However, the present results confirmed that the terminal catabolism of the higher polyamines (SPM and SPD) to DAP was also active in the leaves of dwarf genotypes (Rht 3) treated with SPM, as dramatic increase of DAP content was observed in the SPM-treated Rht 3 plants, both in the leaves and in the roots.

Interestingly, the three genotypes showed partly different pattern regarding the changes in the level of individual polyamines after exogenous polyamine treatments. Remarkable differences were found between Rht and Rht 3. The lowest PUT and SPD accumulation was found in the leaves of Rht 3 after each of treatments (compared to the wild type Rht). At the same time the highest SPM level in the leaves and the highest total polyamine accumulation in the roots were detected also in the Rht 3 treated with SPM. These differences resulted in distinct PUT/(SPD+SPM) ratio for the Rht lines, as lower PUT/(SPD+SPM) ratio was found after all polyamine treatments, both in the leaves and roots in case of Rht 3 compared to the wild type. Table 1. shows the changes in the PUT/(SPD+SPM) ratio in the three genotypes.

As the higher relative abundance of PUT can be harmful to the plants, the maintenance of the optimal polyamine ratio is important. Differences in the higher polyamine levels are not related directly to the changes in the expression level of polyamine synthesis gene, spermidine synthase $(S P D S)$. The observed distinct polyamine metabolism of Rht 3 line may more likely 
reflect more intensive polyamine exodus from PUT to SPD and SPM, and the catabolism of the higher polyamines to DAP. In addition, to the lower root to shoot translocation of PUT can contribute to the regulation of polyamine pool, which in turn may be responsible for the observed lack of growth inhibition in Rht 3 plant after SPD and SPM treatments.

The polyamines (SPD and SPM) especially at higher concentration $(0.5 \mathrm{mM})$, were found to inhibit the growth parameters and induce oxidative stress in maize and wheat plants due to the high polyamine accumulation, which was accompanied by increased SA levels (Szalai et al., 2017). In the present study, polyamines at $0.5 \mathrm{mM}$ concentration differentially influenced the biomass parameters of Rht lines. PUT treatment had slight beneficial effects on Rht and Rht 1 genotypes, while pronounced positive effects were observed in the case of Rht 3. Positive effect of PUT treatment on shoot fresh and dry weight together with increased $\mathrm{CO}_{2}$ assimilation rate in wheat plants has been also reported (Szalai et al., 2017). Exogenous SPD and SPM inhibited all of the biomass parameters in Rht, but their negative effect was dimished in the roots of Rht 3, and even positive effect of them was found in the shoots of Rht 3. In pea plants it was revealed that polyamines needed for the full expression of GA-induced growth, but the concentration of polyamines not directly correlate with growth. In addition, polyamines may be more important to support cell proliferation rather than elongation in GA-induced growth (Smith et al., 1985). Putrescine and spermine may downregulate genes playing role in gibberellin biosynthesis, while the action of spermidine was found to be the opposite (Anwar et al. 2015). According to these relationship exists between polyamines and GAs; GAs may exert their plant growth regulator effects partly by polyamines. Alteration in the polyamine pool may also influence plant growth, but "the more polyamine, the better" is not always true (Pál et al., 2015). Changes in the 
polyamine content do not replace GA signalling, but, to some extent, may compensate the deficiency in the Rht mutant line.

Especially SPM treatment induced many physiological changes in the wheat lines. The slight but statistically not significantly increasing tendency in the lipid peroxidation found in the roots, suggests that the SPM treatment may induce oxidative stress, as both the terminal catabolism and the back-conversion of the excess of polyamine leads to $\mathrm{H}_{2} \mathrm{O}_{2}$ production. However, this small increment was associated with the induced activities of GR and APX in the roots of wheat plants, with the highest activities in the root of SPM-treated Rht 3 genotype, suggesting that the induced antioxidant system can maintain the optimal redox balance. Based on the results of the antioxidant analyses it may be suggested that Rht 3 responds differently to the accumulation of endogenous SPM, than the wild type.

Proline can be a nitrogen source as well as a stress marker, but its synthesis is partially linked to polyamine synthesis (Majumdar et al., 2016). In other words, if the plant can uptake high amount of polyamines from the nutrition solution, the biosynthetic pathway can be converted to proline formation and not to polyamines. Investigation on tomato cultivars showed that the most drought resistant cultivar had increased degradation of proline, which was associated with increased polyamine synthesis, with a higher concentration of spermidine and spermine, while the most drought sensitive cultivar showed proline accumulation in turn, no rise in polyamine synthesis under stress conditions (Montesinos-Pereira et al., 2014). In tobacco after drought stress decreased PUT and SPD, but increased SPM and proline accumulation was found (Cvikrová et al., 2013). In our recent study (Pál et al., 2018) where proline and PA metabolism were investigated under control and PEG induced osmotic stress conditions, we found that the synthesis of proline and PAs were partly regulated independently and not antagonistically; the 

correlation was found between PUT and proline, while negative relationship was observed between SPD and proline contents. Under the present conditions the proline content increased in all the three genotypes in the SPM-treated plants, both in the leaves and roots. However, different tendencies were observed in the changes in proline and polyamine contents in the leaves and roots. In the Rht 3 leaves, higher proline accumulation but lower PUT and SPD levels were found compared to the wild type, while in the Rht 3 roots lower proline content was accompanied with higher PUT, SPD and SPM levels compared to the wild Rht line.

Several studies have confirmed that polyamines interact in several ways with plant hormones to regulate the growth and development of plants (Alcázar et al., 2010). PUT and ABA were reportedly to be integrated in a positive feedback loop (Takahashi et al., 2010). ABA can up-regulate the expression of polyamine synthesis genes (Minocha et al., 2014), and also can influence the polyamine catabolism by inducing expression of genes encoding polyamine oxidase (Guo et al., 2014). At the same time, polyamines influence ABA synthesis (Marco et al., 2011). The transcriptional regulation of the NCED via PUT accumulation has been reported (Alet et al., 2011; Espasandin et al., 2014). Recent results have suggested that SA treatment influences polyamine synthesis and/or catabolism (Wang and Zhang, 2012). In addition, polyamine treatments, especially in the case of higher polyamines also induced SA accumulation (Szalai et al., 2017). Relationship between auxins and polyamines has been suggested in early studies on root formation (Hausman et al., 1995; Tonon et al., 2001; Mendes et al., 2011). IAA was reported to enhance SPD uptake in the presence of $\mathrm{Ca}^{2+}$ into carrot protoplasts (Kanchanapoom et al., 1991). Some recent studies concluded that relationship between polyamines and auxins exists, but the exact mechanism is still not clear. Overexpression of 
SPMS gene in Arabidopsis resulted in change of the expression of genes involved in IAA synthesis. In addition polyamines can also affect the auxin transport (Gonzalez et al., 2011; Kolotilin et al., 2011; Anwar et al., 2015).

Under the present conditions, the dwarf mutant (Rht 3) usually exhibited lower levels of plant hormones (ABA, IAA and SA). Polyamine-induced hormone accumulation was also lower in the leaves of the Rht 3 line than in the wild type. Changes in the SA content correlated well with the level of its precursor, $t$-CA. Polyamine treatment caused similar changes in ABA content as in its degradation product, PA. Higher levels of $t$-CA, SA and ABA contents were detected in Rht 3 only in the roots of treated with SPM in comparison with Rht line. Lower accumulation of SA and $\mathrm{ABA}$, plant hormones usually linked with plant growth inhibition, in leaves may also be responsible for the dimished negative effect of higher polyamines on the shoot growth parameters observed in Rht 3 genotype. These changes in the hormone contents (SA and $\mathrm{ABA}$ ) were in accordance with gene expression levels, as both $C S$ and $N C E D$ transcript levels were lower in the Rht 3 dwarf mutant compared to the wild type after higher polyamine (SPD and SPM) treatments.

In conclusion, recent results suggest that polyamines are part of the signalling systems in plants. Their synthesis and catabolism are regulated by various factors. The present study indicates that polyamine metabolism and polyamine-related processes differ in Rht near-isogenic wheat lines. Especially the dwarf mutant Rht 3 can be characterized by higher level of PAcatabolic activity, represented, among others, by the higher level of DAP in the leaves of control or SPM-treated plants. The plant responses to excess of polyamines may also be beneficial for dwarf lines as higher biomass production could also be detected after exogenous PUT treatment. Even if there were no substantial differences between the isogenic Rht lines in certain 
physiological parameters, they differ in a response to polyamine treatments. This differences among genotypes include more pronounced responses in activities of some antioxidant enzymes, such as G-POD or APX in the roots of Rht 3. Differences were also found in the levels of hormones, such as SA, IAA or ABA. These results provide an insight into the role of polyamines in plant growth regulation based on the investigation of GA-insensitive Rht mutants. However, it should also be taken into consideration that plant hormones (SA, IAA, GA and ABA) may also interact with each other, so further studies are still needed for better understanding the link between polyamine metabolism and plant growth regulation and signalling processes.

\title{
Acknowledgements
}

This work was financed by the grants of the Hungarian National Scientific Research Foundation (K124472) and the Hungarian-Bulgarian bilateral programme (NKM-4/2018) and the Hungarian-Czech bilateral programme (NKM-16/2018), which are gratefully acknowledged.

\author{
Author contributions \\ Magda Pál was responsible for supervision, polyamine determination, statistical analyses, \\ writing and visualization. Beti Ivanovska, Radwan Khalil and Tímea Oláh were responsible \\ for plant growth, sample preparation for HPLC and for spectrophotometric measurements. Judit \\ Tajti and Tímea Oláh were responsible for RT-PCR analyses, Gabriella Szalai, Kamirán \\ Áron Hamow, Radomira Vaňková and Petr Dobrev for hormone analysis. Radomira \\ Vaňková, Svetlana Landjeva and Tibor Janda is responsible for review and editing.
}

\section{Conflict of Interest Statement}

The authors declare that they have no conflicts of interest. 


\section{References:}

Ádám, A.L., Bestwick, C.S., Barna, B., Mansfield, J.W., 1995. Enzymes regulating the accumulation of active oxygen species during the hypersensitive reaction of bean to Pseudomonas syringae pv. phaseolicola. Planta 197, 240-249. https://doi.org/10.1007/BF00202643

Alcázar, R., Altabella, T., Marco, F., Bortolotti, C., Reymond, M., Koncz, C., Carrasco, P., Tiburcio, A., 2010. Polyamines: Molecules with regulatory functions in plant abiotic stress tolerance. Planta. https://doi.org/10.1007/s00425-010-1130-0

Alcázar, R., Cuevas, J.C., Patron, M., Altabella, T., Tiburcio, A.F., 2006. Abscisic acid modulates polyamine metabolism under water stress in Arabidopsis thaliana. Physiol Plant. 128, 448-455. https://doi.org/10.1111/j.1399-3054.2006.00780.x

Alcázar, R., García-Martínez, J.L., Cuevas, J.C., Tiburcio, A.F., Altabella, T., 2005. Overexpression of $A D C 2$ in Arabidopsis induces dwarfism and late-flowering through GA deficiency. Plant J 43, 425-436. https://doi.org/10.1111/j.1365-313X.2005.02465.x

Alet, A.I., Sanchez, D.H., Cuevas, J.C., del Valle, S., Altabella, T., Tiburcio, A.F., Marco, F., Ferrando, A., Espasandín, F.D., González, M.E., Carrasco, P., Ruiz, O.A., 2011. Putrescine accumulation in Arabidopsis thaliana transgenic lines enhances tolerance to dehydration and freezing stress. Plant Signal Behav 6, 278-286. https://doi.org/10.4161/psb.6.2.14702

Anwar, R., Mattoo, A.K., Handa, A.K., 2015. Polyamine interactions with plant hormones: Crosstalk at several levels, in: Polyamines. Springer Japan, Tokyo, pp. 267-302. https://doi.org/10.1007/978-4-431-55212-3_22 
Asthir, B., Duffus, C., Spoor, W. 2004. Correlation of gibberellin-induced growth, polyamine levels and amine oxidases in epicotyl, root and leaf blade of barley seedlings. Plant Growth Regul 42, 193-201. https://doi.org/10.1023/B:GROW.000

Bates, L.S., Waldren, R.P., Teare, I.D., 1973. Rapid determination of free proline for water-stress studies. Plant Soil 39, 205-207. https://doi.org/10.1007/BF00018060

Chen, Z., Zheng, Z., Huang, J., Lai, Z., Fan, B., 2009. Biosynthesis of salicylic acid in plants. Plant Signal Behav 4, 493-6. https://doi.org/10.4161/PSB.4.6.8392

Choudhary, S.P., Oral, H. V., Bhardwaj, R., Yu, J.-Q., Tran, L.-S.P., 2012. Interaction of brassinosteroids and polyamines enhances copper stress tolerance in Raphanus sativus. $\mathrm{J}$ Env. Qual 63, 5659-5675. https://doi.org/10.1093/jxb/ers219

Cvikrová, M., Gemperlová, L., Martincová, O., Vanková, R., 2013. Effect of drought and combined drought and heat stress on polyamine metabolism in proline-over-producing $\begin{array}{llllll}\text { tobacco plants. Plant } & \text { Physiol }\end{array}$ https://doi.org/10.1016/j.plaphy.2013.08.005

Dai, Y.R., Kaur-Sawhney, R., Galston, A.W., 1982. Promotion by gibberellic acid of polyamine biosynthesis in internodes of light-grown dwarf peas. Plant Physiol 69, 103-106. https://doi.org/10.1104/pp.69.1.103

Daviere, J.-M., Achard, P., 2013. Gibberellin signaling in plants. Development 140, 1147-1151. https://doi.org/10.1242/dev.087650

Dobrikova, A.G., Yotsova, E.K., Börner, A., Landjeva, S.P., Apostolova, E.L., 2017. The wheat mutant DELLA-encoding gene ( Rht-Blc ) affects plant photosynthetic responses to $\begin{array}{llllll}\text { cadmium } & \text { stress. } & \text { Plant } & \text { Physiol }\end{array}$ https://doi.org/10.1016/j.plaphy.2017.02.015 
Espasandin, F.D., Maiale, S.J., Calzadilla, P., Ruiz, O.A., Sansberro, P.A., 2014. Transcriptional regulation of 9-cis-epoxycarotenoid dioxygenase (NCED) gene by putrescine accumulation positively modulates $\mathrm{ABA}$ synthesis and drought tolerance in lotus tenuis plants. Plant Physiol Biochem 76, 29-35. https://doi.org/10.1016/j.plaphy.2013.12.018

Flintham, J.E., Borner, A., Worland, A.J., Gale, M.D., 1997. Optimizing wheat grain yield: effects of $R h t$ (gibberellin-insensitive) dwarfing genes. J Agric Sci 128, 11-25.

Gallé, Á., Csiszár, J., Benyó, D., Laskay, G., Leviczky, T., Erdei, L., Tari, I., 2013. Isohydric and anisohydric strategies of wheat genotypes under osmotic stress: Biosynthesis and function of ABA in stress responses. J Plant Physiol 170, 1389-1399. https://doi.org/10.1016/j.jplph.2013.04.010

Giménez, M.J., Pistón, F., Atienza, S.G., 2011. Identification of suitable reference genes for normalization of qPCR data in comparative transcriptomics analyses in the Triticeae. Planta 233: 163-173. https://doi.org/10.1007/s00425-010-1290-y

Gondor, O.K., Szalai, G., Kovács, V., Janda, T., Pál, M., 2016. Relationship between polyamines and other cold-induced response mechanisms in different cereal species. J. Agron. Crop Sci. 202, 217-230. https://doi.org/10.1111/jac.12144

Gonzalez, M.E., Marco, F., Minguet, E.G., Carrasco-Sorli, P., Blazquez, M.A., Carbonell, J., Ruiz, O.A., Pieckenstain, F.L., 2011. Perturbation of spermine synthase gene expression and transcript profiling provide new insights on the role of the tetraamine spermine in Arabidopsis defense against Pseudomonas viridiflava. Plant Physiol 156, 2266-2277. https://doi.org/10.1104/pp.110.171413

Guo, Z., Tan, J., Zhuo, C., Wang, C., Xiang, B., Wang, Z., 2014. Abscisic acid, $\mathrm{H}_{2} \mathrm{O}_{2}$ and nitric oxide interactions mediated cold-induced S -adenosylmethionine synthetase in Medicago 
sativa subsp. falcata that confers cold tolerance through up-regulating polyamine oxidation.

Plant Biotech J 12, 601-612. https://doi.org/10.1111/pbi.12166

Harberd, N.P., Belfield, E., Yasumura, Y., 2009. The angiosperm gibberellin-GID1-DELLA growth regulatory mechanism: How an 'inhibitor of an inhibitor' enables flexible response to fluctuating environments. Plant Cell 21, 1328-1339. https://doi.org/10.1105/tpc.109.066969

Hausman, J.F., Kevers, C., Gaspar, T., 1995. Auxin-polyamine interaction in the control of the rooting inductive phase of poplar shoots in vitro. Plant Sci 110, 63-71. https://doi.org/10.1016/0168-9452(95)04193-X

Hedden, P., Thomas, S.G., 2012. Gibberellin biosynthesis and its regulation. Biochem J 444, 1125. https://doi.org/10.1042/bj20120245

Hoogendoorn, J., Rickson, J.M., Gale, M.D., 1990. Differences in leaf and stem anatomy related to plant height of tall and dwarf wheat (Triticum aestivum L.). J Plant Physiol 136, 72-77. https://doi.org/10.1016/S0176-1617(11)81618-4

Janda, T., Szalai, G., Tari, I., Páldi, E., 1999. Hydroponic treatment with salicylic acid decreases the effects of chilling injury in maize (Zea mays L.) plants. Planta 208, 175-180. https://doi.org/10.1007/s004250050547

Jiménez-Bremont, J.F., Marina, M., Guerrero-González, M. de la L., Rossi, F.R., SánchezRangel, D., Rodrí-guez-Kessler, M., Ruiz, O.A., Gárriz, A., 2014. Physiological and molecular implications of plant polyamine metabolism during biotic interactions. Front Plant Sci 5, 95. https://doi.org/10.3389/fpls.2014.00095

Kanchanapoom, M., Antognoni, F., Pistocchi, R., Bagni, N., 1991. Effect of auxins on spermidine uptake into carrot protoplasts. Physiol Plant. 82, 19-23. 
https://doi.org/10.1111/j.1399-3054.1991.tb02897.x

Kaur-Sawhney, R., Dai, Y.R., Galston, A.W., 1986. Effect of inhibitors of polyamine biosynthesis on gibberellin-induced internode growth in light-grown dwarf peas. Plant Cell Physiol 27, 253-260. https://doi.org/10.1093/oxfordjournals.pcp.a077097

Kocheva, K., Nenova, V., Karceva, T., Petrov, P., Georgiev, G.I., Börner, A., Landjeva, S., 2014. Changes in water status, membrane stability and antioxidant capacity of wheat seedlings carrying different $R h t-B l$ dwarfing alleles under drought stress. J Agron Crop Sci 200, 83-91. https://doi.org/10.1111/jac.12047

Kocheva, K. V., Landjeva, S.P., Georgiev, G.I., 2014. Variation in ion leakage parameters of two wheat genotypes with different $R h t-B 1$ alleles in response to drought. J Biosci 39, 753-759. https://doi.org/10.1007/s12038-014-9471-7

Kolotilin, I., Koltai, H., Bar-Or, C., Chen, L., Nahon, S., Shlomo, H., Levin, I., Reuveni, M., 2011. Expressing yeast $S A M d c$ gene confers broad changes in gene expression and alters fatty acid composition in tomato fruit. Physiol Plant. 142, 211-223. https://doi.org/10.1111/j.1399-3054.2011.01458.x

Kovács, V., Gondor, O.K., Szalai, G., Darkó, É., Majláth, I., Janda, T., Pál, M., 2014. Synthesis and role of salicylic acid in wheat varieties with different levels of cadmium tolerance. $\mathrm{J}$ Hazard Mater 280, 12-19. https://doi.org/10.1016/j.jhazmat.2014.07.048

Krishnan, S., Merewitz, E.B., 2017. Polyamine application effects on gibberellic acid content in creeping bentgrass during drought stress. J Am Soc Hortic Sci 142, 135-142. https://doi.org/10.21273/JASHS03991-16

Livak, K.J., Schmittgen, T.D., 2001. Analysis of relative gene expression data using real-time quantitative PCR and the $2^{-\Delta \Delta C T}$ method. Methods 25, 402-408. 
https://doi.org/10.1006/meth.2001.1262

Majumdar, R., Barchi, B., Turlapati, S.A., Gagne, M., Minocha, R., Long, S., Minocha, S.C., 2016. Glutamate, ornithine, arginine, proline, and polyamine metabolic interactions: The pathway is regulated at the post-transcriptional Level. Front Plant Sci 7, 78. https://doi.org/10.3389/fpls.2016.00078

Marco, F., Alcázar, R., Tiburcio, A.F., Carrasco, P., 2011. Interactions between polyamines and abiotic stress pathway responses unraveled by transcriptome analysis of polyamine overproducers. OMICS 15, 775-781. https://doi.org/10.1089/omi.2011.0084

Mendes, A.F.S., Cidade, L.C., Otoni, W.C., Soares-Filho, W.S., Costa, M.G.C., 2011. Role of auxins, polyamines and ethylene in root formation and growth in sweet orange. Biol Plant. 55, 375-378. https://doi.org/10.1007/s10535-011-0058-y

Minocha, R., Majumdar, R., Minocha, S.C., 2014. Polyamines and abiotic stress in plants: a complex relationship. Front Plant Sci 5, 175. https://doi.org/10.3389/fpls.2014.00175

Montesinos-Pereira, D., Barrameda-Medina, Y., Romero, L., Ruiz, J.M., Sánchez-Rodríguez, E., 2014. Genotype differences in the metabolism of proline and polyamines under moderate drought in tomato plants. Plant Biol 16, 1050-1057.

Németh, M., Janda, T., Horváth, E., Páldi, E., Szalai, G., 2002. Exogenous salicylic acid increases polyamine content but may decrease drought tolerance in maize. Plant Sci 162, 569-574. https://doi.org/10.1016/S0168-9452(01)00593-3

Nenova, V.R., Kocheva, K. V., Petrov, P.I., Georgiev, G.I., Karceva, T. V., Börner, A., Landjeva, S.P., 2014. Wheat Rht-B1 dwarfs exhibit better photosynthetic response to water deficit at seedling stage compared to the wild type. J Agron Crop Sci 200, 434-443. https://doi.org/10.1111/jac.12090 
Pál, M., Horváth, E., Janda, T., Páldi, E., Szalai, G., 2005. Cadmium stimulates the accumulation of salicylic acid and its putative precursors in maize (Zea mays) plants. Physiol Plant. 125, 356-364. https://doi.org/10.1111/j.1399-3054.2005.00545.x

Pál, M., Szalai, G., Janda, T., 2015. Speculation: Polyamines are important in abiotic stress signaling. Plant Sci. https://doi.org/10.1016/j.plantsci.2015.05.003

Pál, M., Tajti, J., Szalai, G., Peeva, V., Végh, B., Janda, T., 2018. Interaction of polyamines, abscisic acid and proline under osmotic stress in the leaves of wheat plants. Sci Rep. https://doi.org/10.1038/s41598-018-31297-6

Paolacci, A.R., Tanzarella, O.A., Porceddu, E., Ciaffi, M., 2009. Identification and validation of reference genes for quantitative RT-PCR normalization in wheat. BMC Mol Biol 10, 11. https://doi.org/10.1186/1471-2199-10-11

Smith, M.A., Davies, P.J., Reid, J.B., 1985. Role of polyamines in gibberellin-induced internode growth in peas. Plant Physiol 78, 92-99. https://doi.org/10.1104/pp.78.1.92

Smith, I.K., Vierheller, T.L., Thorne, C.A., 1988. Assay of glutathione reductase in crude tissue homogenates using 5,5'-dithiobis(2-nitrobenzoic acid). Anal Biochem 175, 408-413. https://doi.org/10.1016/0003-2697(88)90564-7

Szalai, G., Janda, K., Darkó, É., Janda, T., Peeva, V., Pál, M., 2017. Comparative analysis of polyamine metabolism in wheat and maize plants. Plant Physiol Biochem 112, 239-250. https://doi.org/10.1016/j.plaphy.2017.01.012

Szepesi, Á., Gémes, K., Orosz, G., Peto, A., Takács, Z., Vorák, M., Tari, I., 2011. Interaction between salicylic acid and polyamines and their possible roles in tomato hardening processes. Acta Biol Szeged 55, 165-166. https://doi.org/10.07/s00726-009-0322-z

Takács, Z., Poór, P., Tari, I., 2016. Comparison of polyamine metabolism in tomato plants 
Takahashi, Y., Cong, R., Sagor, G.H.M., Niitsu, M., Berberich, T., Kusano, T., 2010. Characterization of five polyamine oxidase isoforms in Arabidopsis thaliana. Plant Cell Rep 29, 955-965. https://doi.org/10.1007/s00299-010-0881-1

Thomas, J.C., Perron, M., Davies, E.C., 2004. Genetic responsiveness to copper in the Ice Plant, Mesembryanthemum crystallinum. Plant Sci 167, 259-266. https://doi.org/10.1016/J.PLANTSCI.2004.03.022

Tonon, G., Kevers, C., Gaspar, T., 2001. Changes in polyamines, auxins and peroxidase activity during in vitro rooting of Fraxinus angustifolia shoots: An auxin-independent rooting model. Tree Physiol 21, 655-663. https://doi.org/10.1093/treephys/21.10.655

Vrhovsek, U., Masuero, D., Gasperotti, M., Franceschi, P., Caputi, L., Viola, R., Mattivi, F., 2012. A versatile targeted metabolomics method for the rapid quantification of multiple classes of phenolics in fruits and beverages, in: J Agric Food Chem. pp. 8831-8840. https://doi.org/10.1021/jf2051569

Wang, W., Wang, X., Huang, M., Cai, J., Zhou, Q., Dai, T., Cao, W., Jiang, D. 2018. Hydrogen peroxide and abscisic acid mediate salicylic acid-induced freezing tolerance in wheat. Front Plant Sci, 9, 1137. https://doi.org/10.3389/fpls.2018.01137

Wang, X., Zhang, Y., 2012. Regulation of salicylic acid on polyamine synthesize under $\mathrm{NaCl}$ stress in leaves of the yali pear. Res J Appl Sci Eng Technol 4, 3704-3708. 
Table 1. Changes in the PUT/(SPD+SPM) ratio after $0.5 \mathrm{mM}$ putrescine (PUT), spermidine (SPD) or spermine (SPM) treatments in the leaves and roots of wheat plants. The highest values both in the leaves and roots are highlighted.

\begin{tabular}{lcccc|cccc} 
& \multicolumn{4}{c}{ Leaves } & \multicolumn{5}{c}{ Roots } \\
\cline { 2 - 9 } & C & PUT & SPD & SPM & C & PUT & SPD & SPM \\
\cline { 2 - 9 } Rht & 0.152 & 0.248 & $\mathbf{0 . 3 8 9}$ & 0.362 & 4.981 & $\mathbf{6 7 . 4 2 3}$ & 5.642 & 3.121 \\
Rht 1 & 0.168 & 0.205 & $\mathbf{0 . 2 3 1}$ & 0.160 & 9.791 & $\mathbf{1 2 . 2 5 3}$ & 10.114 & 2.874 \\
Rht 3 & $\mathbf{0 . 2 3 2}$ & 0.200 & 0.144 & 0.198 & 2.961 & $\mathbf{1 1 . 0 3 5}$ & 3.140 & 2.029 \\
\hline
\end{tabular}


Table 2. MRM transitions used for LC-MS/MS analysis.

\begin{tabular}{|l|c|c|c|c|c|c|c|}
\hline $\begin{array}{l}\text { Analyte and } \\
\text { transition order }\end{array}$ & $\begin{array}{c}\text { Q1 } \\
\mathbf{m} / \mathbf{z}\end{array}$ & $\begin{array}{c}\mathbf{Q 3} \\
\mathbf{m} / \mathbf{z}\end{array}$ & $\begin{array}{c}\text { cone } \\
\text { voltage } \\
(\mathbf{V})\end{array}$ & $\begin{array}{c}\text { Collision } \\
\text { Energy } \\
(\mathbf{e V})\end{array}$ & $\begin{array}{c}\text { RT } \\
(\mathbf{m i n s})\end{array}$ & polarity & $\begin{array}{c}\text { Used for } \\
\text { quantitation }\end{array}$ \\
\hline Abcisic Acid 1 & 263.1 & 153.0 & 20 & 10 & 7.17 & US neg & YES \\
\hline Abcisic Acid 2 & 263.1 & 204.0 & 20 & 20 & 7.17 & US neg & \\
\hline Abcisic Acid 3 & 263.1 & 201.1 & 20 & 18 & 7.17 & US neg & \\
\hline Abcisic Acid 4 & 263.1 & 219.1 & 20 & 12 & 7.17 & US neg & \\
\hline Indole-3-acetic acid 1 & 176.1 & 130.1 & 25 & 14 & 5.96 & US pos & YES \\
\hline Indole-3-acetic acid 2 & 176.1 & 103.1 & 25 & 34 & 5.96 & US pos & \\
\hline Indole-3-acetic acid 3 & 176.1 & 77.1 & 25 & 50 & 5.96 & US pos & \\
\hline Phaseic Acid 1 & 279.1 & 139.0 & 25 & 12 & 5.12 & US neg & YES \\
\hline Phaseic Acid 2 & 279.1 & 205.2 & 25 & 14 & 5.12 & US neg & \\
\hline Phaseic Acid 3 & 279.1 & 168.2 & 25 & 14 & 5.12 & US neg & \\
\hline Salicylic Acid 1 & 137.0 & 93.0 & 20 & 12 & 5.84 & US neg & YES \\
\hline Salicylic Acid 2 & 137.0 & 64.9 & 20 & 24 & 5.84 & US neg & \\
\hline TransCinnamicAcid 1 & 131.0 & 103.0 & 40 & 12 & 7.52 & US pos & YES \\
\hline TransCinnamicAcid 2 & 131.0 & 76.9 & 40 & 20 & 7.52 & US pos & \\
\hline TransCinnamicAcid 3 & 149.0 & 103.0 & 25 & 17 & 7.52 & US pos & \\
\hline
\end{tabular}


Table 3. Gene-specific and housekeeping primers.

\begin{tabular}{|c|c|c|c|}
\hline Gene name & \multicolumn{2}{|r|}{ Primer sequences $\left(5^{\prime} \rightarrow 3^{\prime}\right)$} & Reference \\
\hline Ta2291 & Forward & GCTCTCCAACAACATTGCCAAC & \multirow{2}{*}{ (Paolacci et al., 2009) } \\
\hline (encoding ADP-ribosylation factor) & Reverse & GCTTCTGCCTGTCACATACGC & \\
\hline \multirow{2}{*}{ TaSPDS } & Forward & AGGTATTCAAGGGTGGCGTG & \multirow{2}{*}{ own design } \\
\hline & Reverse & TGGGTTCACAGGAGTCAGGA & \\
\hline \multirow{2}{*}{ TaNCED } & Forward & CCTCGAAGCCCAGCACTAAT & \multirow{2}{*}{ (Gallé et al., 2013) } \\
\hline & Reverse & GAGAGCGAGAGGTCCAATGG & \\
\hline \multirow{2}{*}{$\mathrm{TaCS}$} & Forward & GCGGCCATCGTCTCCACCAT & \multirow{2}{*}{ (Kovács et al., 2014) } \\
\hline & Reverse & GGCCGAGGTACAGGGAGGGA & \\
\hline
\end{tabular}




\section{Legends}

Figure 1. Effects of 7-day $0.5 \mathrm{mM}$ putrecine (PUT), spermidine (SPD) or spermine (SPM) treatments on the putrescine: PUT (A), spermidine: SPD (B), spermine: SPM (C) or 1,3-diaminopropane: DAP (D) contents in the leaves of wheat plants. Data represent mean values $\pm S D, n=5$. Different letters indicate significant differences at $\mathrm{P} \leq 0.05$ level.

Figure 2. Effects of 7-day 0.5 mM putrecine (PUT), spermidine (SPD) or spermine (SPM) treatments on the putrescine: PUT (A), spermidine: SPD (B), spermine: SPM (C) or 1,3-diaminopropane: DAP (D) contents in the roots of wheat plants. Data represent mean values $\pm S D, n=5$. Different letters indicate significant differences at $\mathrm{P} \leq 0.05$ level.

Figure 3. Effects of 7-day 0.5 mM putrecine (PUT), spermidine (SPD) or spermine (SPM) treatments on biomass parameters (shoot length: A, shoot fresh weight (B) root length (C) and root fresh weight (D) of wheat genotypes (Rht: wild type, Rht 1: semidwarf and Rht 3: dwarf). Data represent mean values \pm SD, $\mathrm{n}=15$. Different letters indicate significant differences at $\mathrm{P} \leq 0.05$ level.

Figure 4. Influence of 7-day $0.5 \mathrm{mM}$ putrecine (PUT), spermidine (SPD) or spermine (SPM) treatments on biomass parameters (shoot length, root length, shoot fresh weight and root fresh weight) of wheat genotypes (Rht: wild type, Rht1: semidwarf and Rht3: dwarf) expressed in the percentage of the adequate control values.

Figure 5. Effects of 7-day 0.5 mM putrecine (PUT), spermidine (SPD) or spermine (SPM) treatments on the lipid peroxidation (A) and on the proline content (B) in the leaves and roots of wheat plants. Data represent mean values $\pm \mathrm{SD}, \mathrm{n}=5$. Different letters indicate significant differences at $\mathrm{P} \leq 0.05$ level.

Figure 6. Effects of 7-day 0.5 mM putrecine (PUT), spermidine (SPD) or spermine (SPM) treatments on the glutathione reductase (GR), guaiacol peroxidase (G-POD) and ascorbate peroxidase (APX) activity in the leaves (A, C and E) and in the roots $(B, D$ and $F)$ of wheat plants. Data represent mean values $\pm \mathrm{SD}$, $\mathrm{n}=5$. Different letters indicate significant differences at $\mathrm{P} \leq 0.05$ level.

Figure 7. Effects of 7-day 0.5 mM putrecine (PUT), spermidine (SPD) or spermine (SPM) treatments on the levels of trans-cinnamic acid ( $t$-CA) and salicylic acid (SA) in the leaves (A and C) and in the roots 
(B and D) of wheat plants. Data represent mean values $\pm S D, n=5$. Different letters indicate significant differences at $\mathrm{P} \leq 0.05$ level.

Figure 8. Effects of 7-day 0.5 mM putrecine (PUT), spermidine (SPD) or spermine (SPM) treatments on the auxin (IAA) content in the leaves (A) and in the roots (B) of wheat plants. Data represent mean values $\pm \mathrm{SD}, \mathrm{n}=5$. Different letters indicate significant differences at $\mathrm{P} \leq 0.05$ level.

Figure 9. Effects of 7-day 0.5 mM putrecine (PUT), spermidine (SPD) or spermine (SPM) treatments on the levels of abscisic acid (ABA) and phaseic acid (PA) in the leaves (A and C) and in the roots (B and D) of wheat plants. Data represent mean values $\pm S D, n=5$. Different letters indicate significant differences at $\mathrm{P} \leq 0.05$ level.

Figure 10. Effects of 7-day 0.5 mM putrecine (PUT), spermidine (SPD) or spermine (SPM) treatments on the gene expression level of spermidine synthase $(S P D S)$ in the leaves (A) and in the roots (B) of wheat plants. The relative gene expression values were determined with the $\Delta \Delta \mathrm{Ct}$ method. Every control treatment represents an individual calibrator in the case of each genotype. All reactions were performed in triplicate. Different letters indicate significant differences at $\mathrm{P} \leq 0.05$ level.

Figure 11. Effects of 7-day 0.5 mM putrecine (PUT), spermidine (SPD) or spermine (SPM) treatments on the gene expression level of chorismate synthase $(C S)$ in the leaves (A) and in the roots (B) of wheat plants. The relative gene expression values were determined with the $\Delta \Delta \mathrm{Ct}$ method. Every control treatment represents an individual calibrator in the case of each genotype. All reactions were performed in triplicate. Different letters indicate significant differences at $\mathrm{P} \leq 0.05$ level.

Figure 12. Effects of 7-day 0.5 mM putrecine (PUT), spermidine (SPD) or spermine (SPM) treatments on the gene expression level of 9-cis-epoxycarotenoid dioxygenase gene $(N C E D)$ in the leaves $(\mathrm{A})$ and in the roots (B) of wheat plants. The relative gene expression values were determined with the $\Delta \Delta \mathrm{Ct}$ method. Every control treatment represents an individual calibrator in the case of each genotype. All reactions were performed in triplicate. Different letters indicate significant differences at $\mathrm{P} \leq 0.05$ level. 


\section{Author contributions}

Magda Pál was responsible for supervision, polyamine determination, statistical analyses, writing and visualization. Beti Ivanovska, Radwan Khalil and Tímea Oláh were responsible for plant growth, sample preparation for HPLC and for spectrophotometric measurements. Judit Tajti and Tímea Oláh were responsible for RT-PCR analyses, Gabriella Szalai, Kamirán Áron Hamow, Radomira Vaňková and Petr Dobrev for hormone analysis. Radomira Vaňková, Svetlana Landjeva and Tibor Janda is responsible for review and editing. 


\section{Figure 1}

Click here to download high resolution image
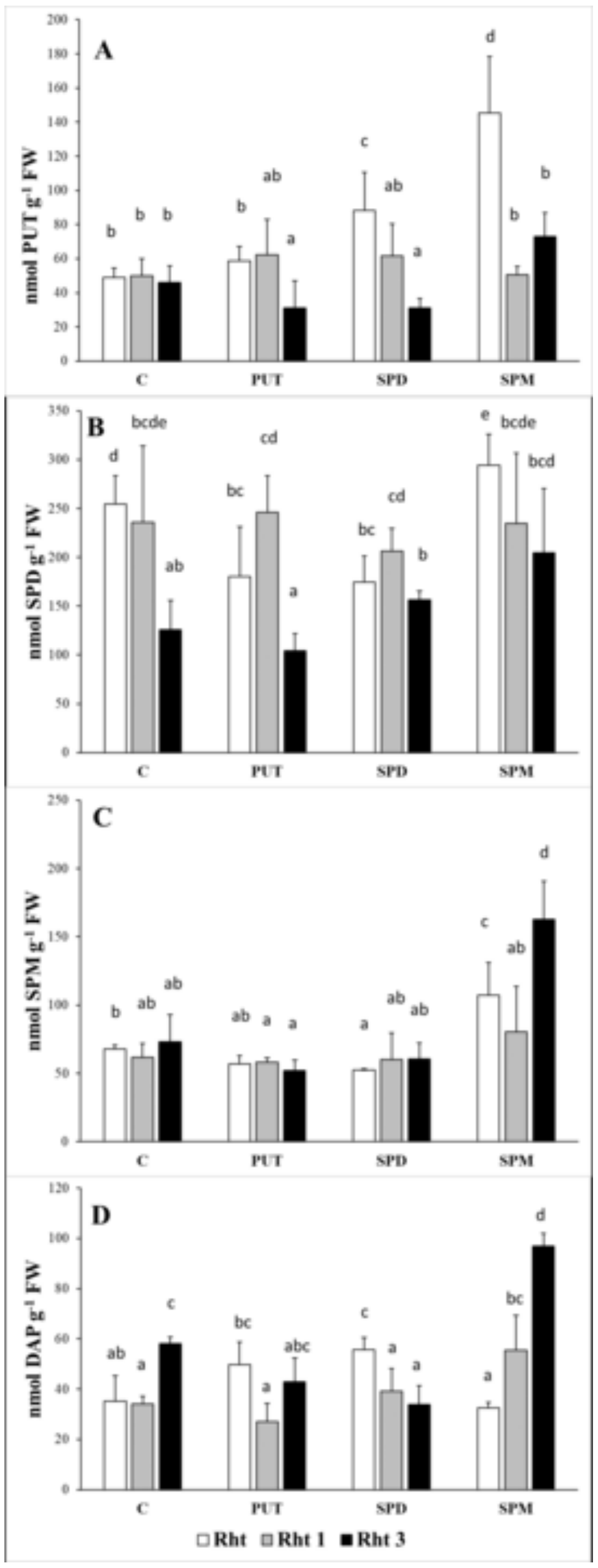


\section{Figure 2}

Click here to download high resolution image
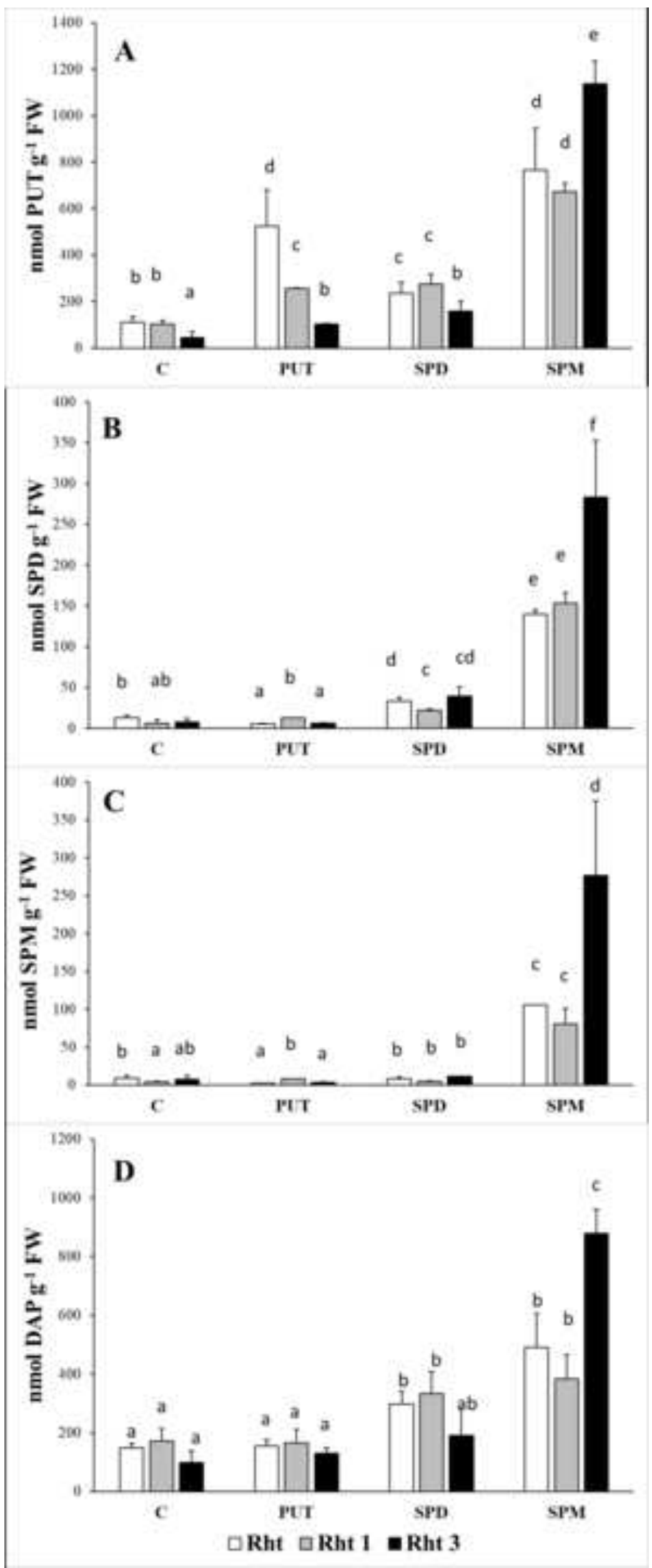

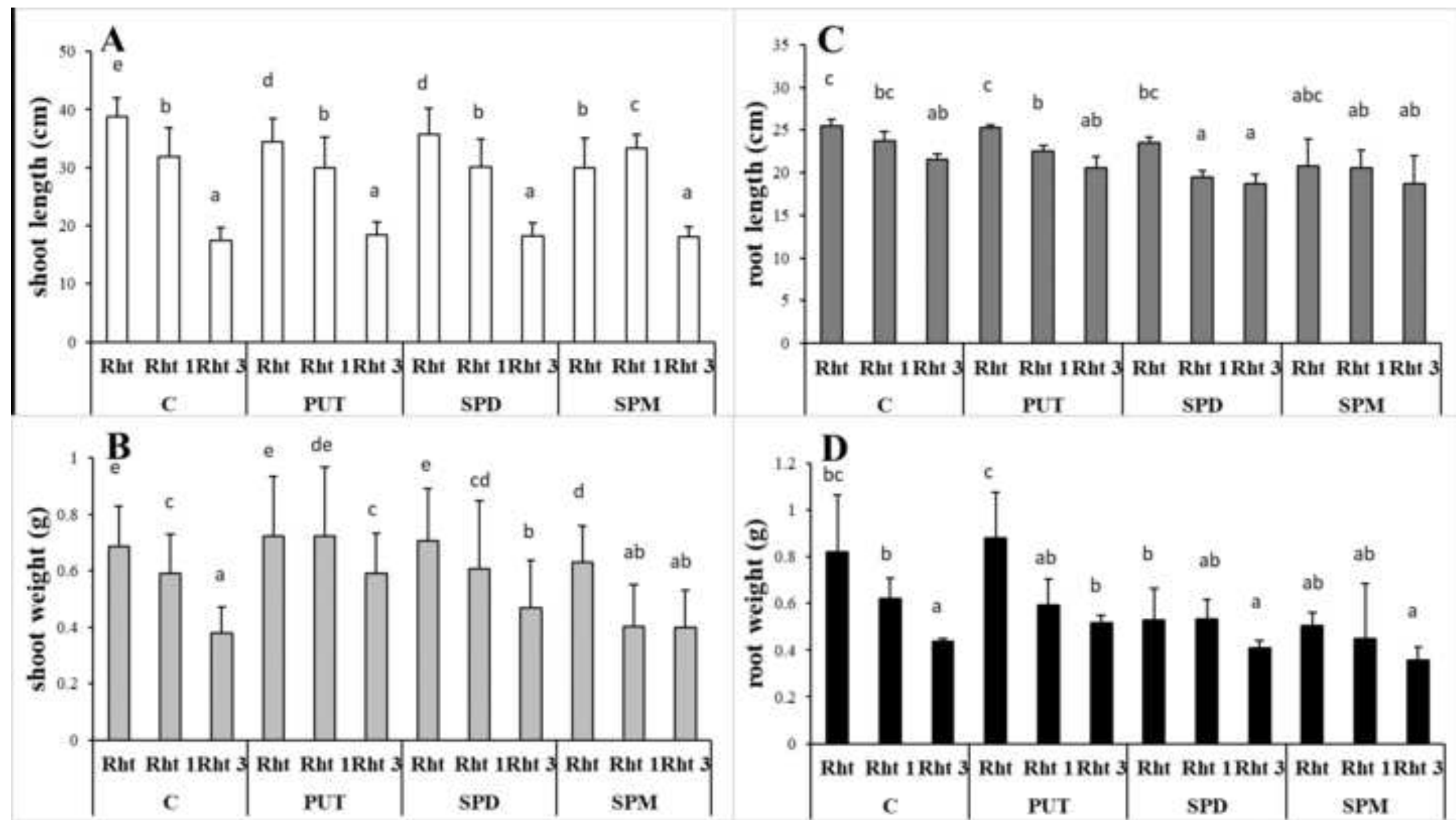


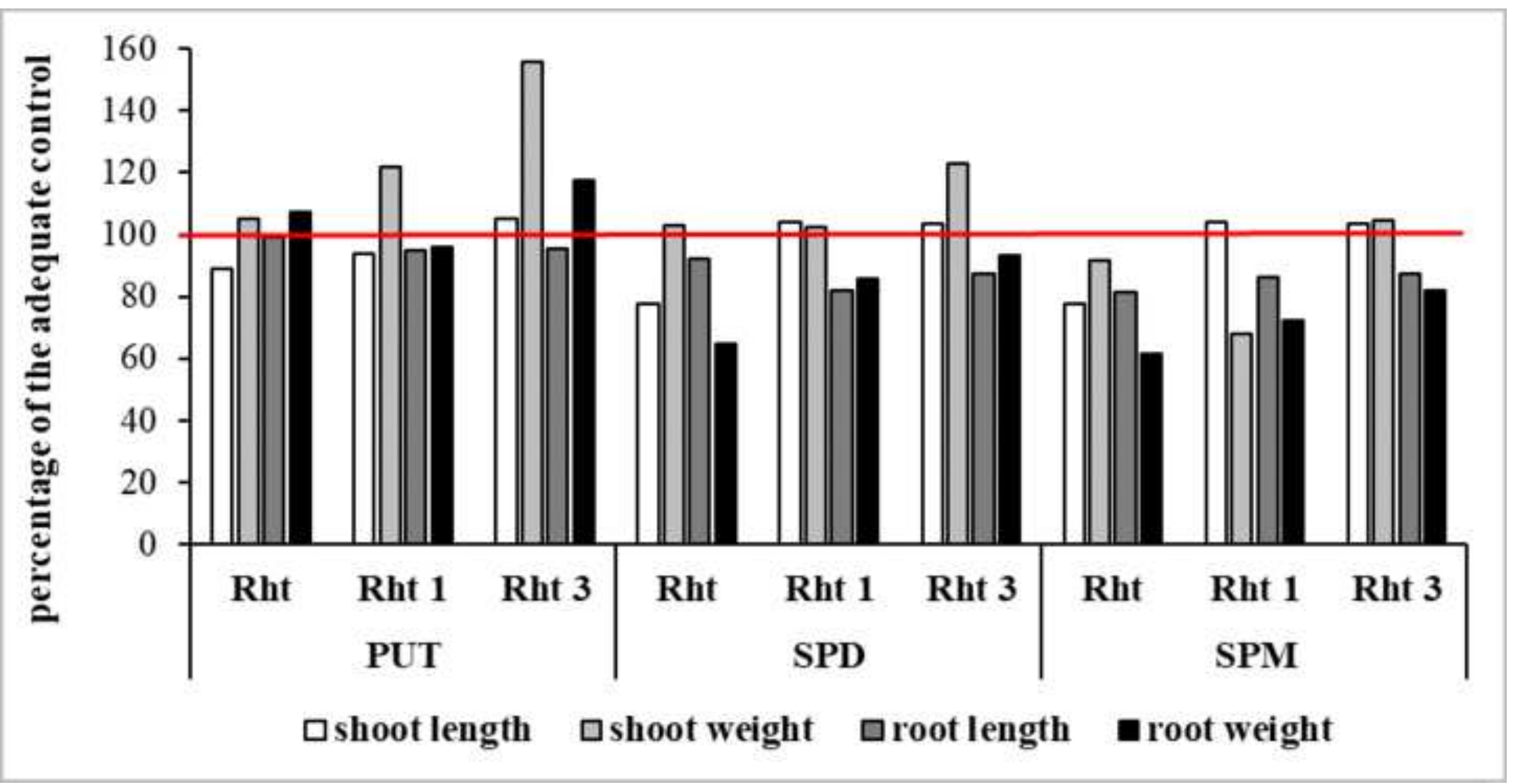




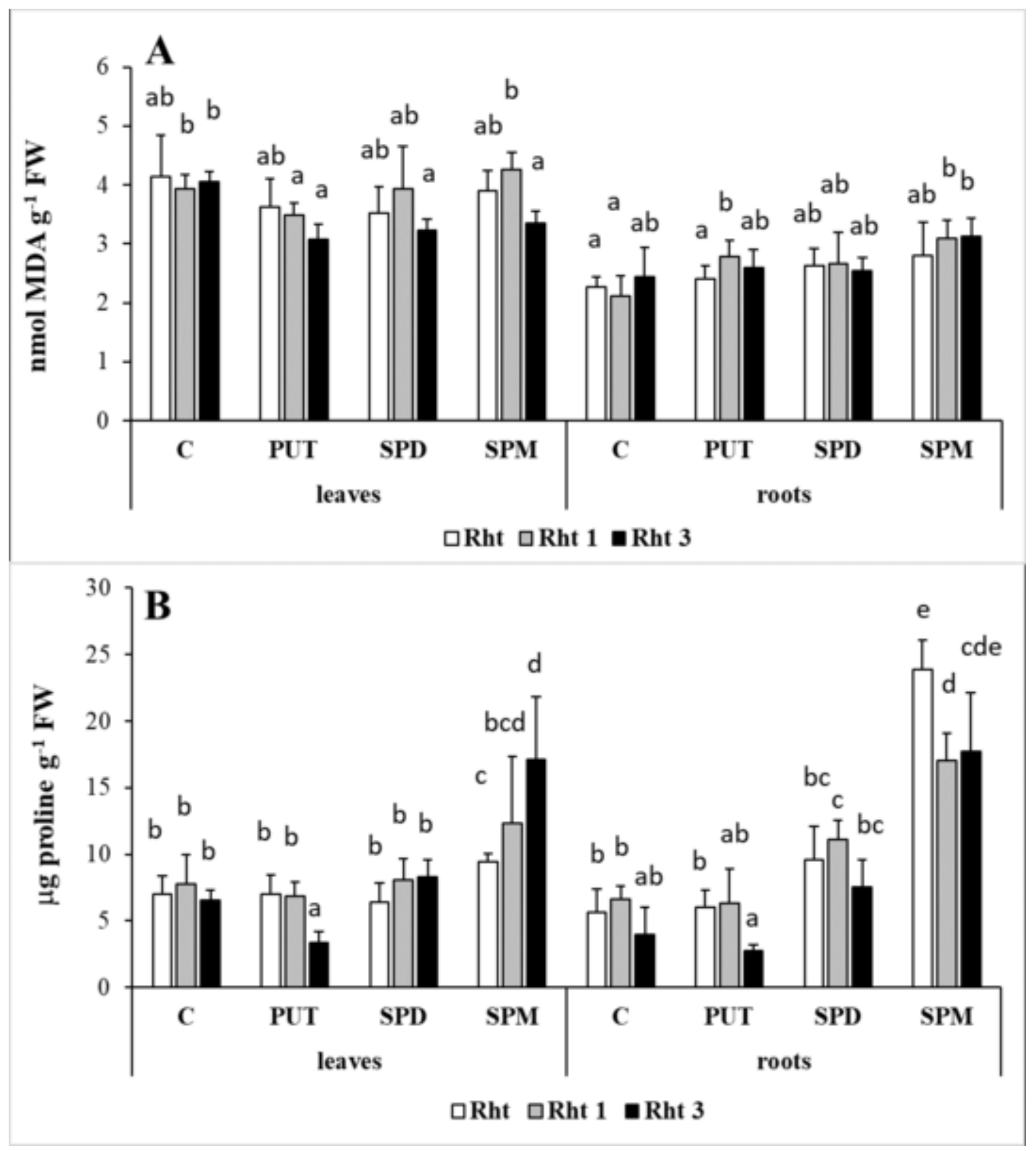



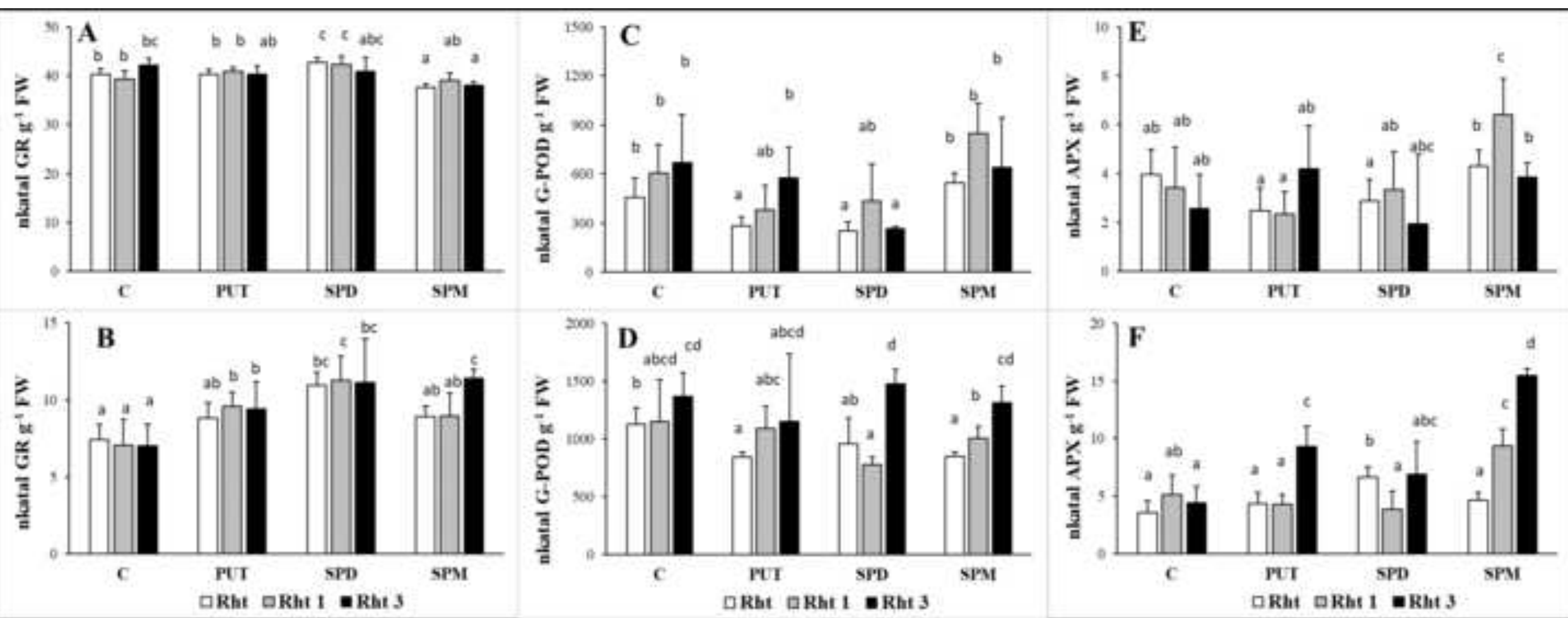

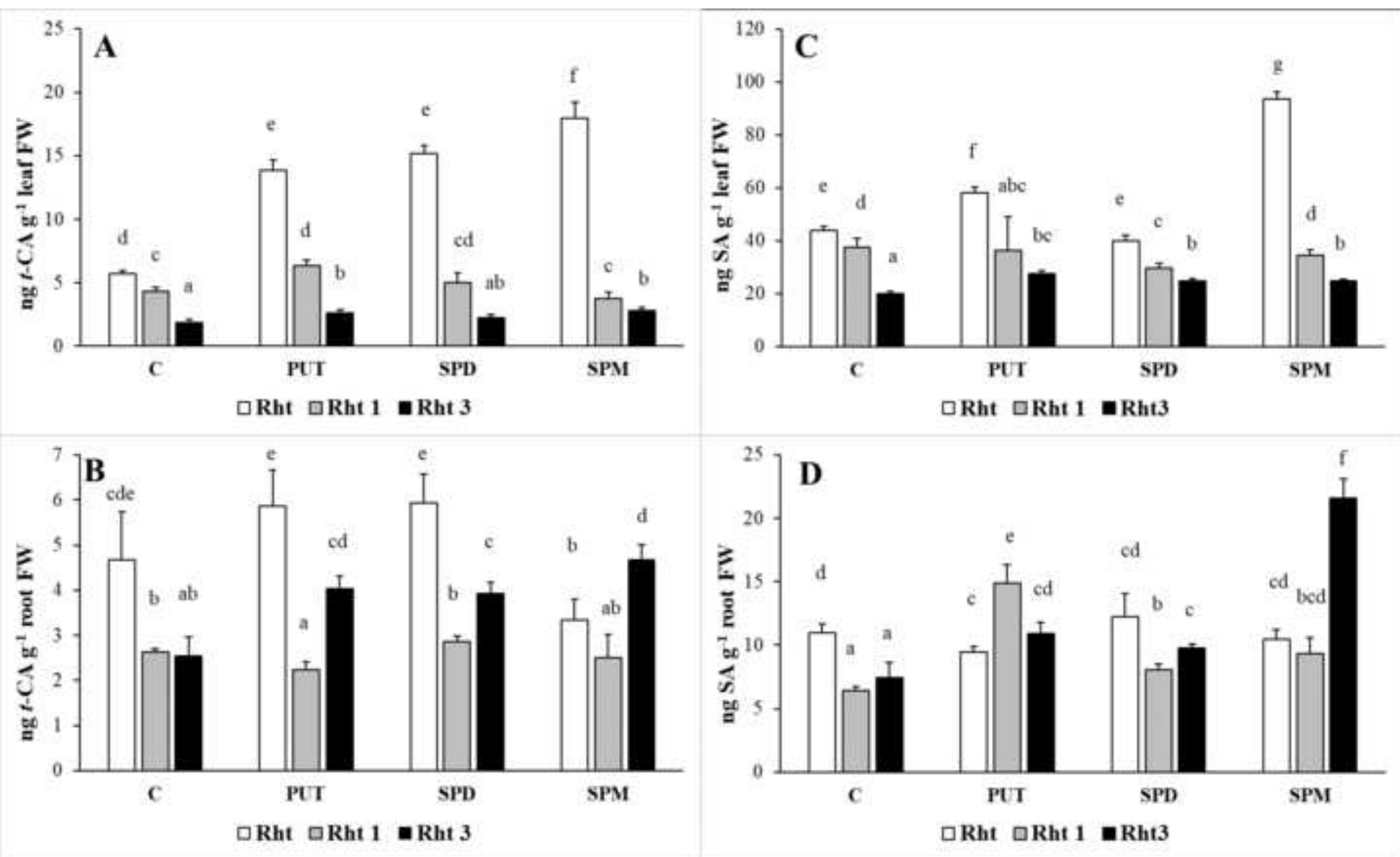

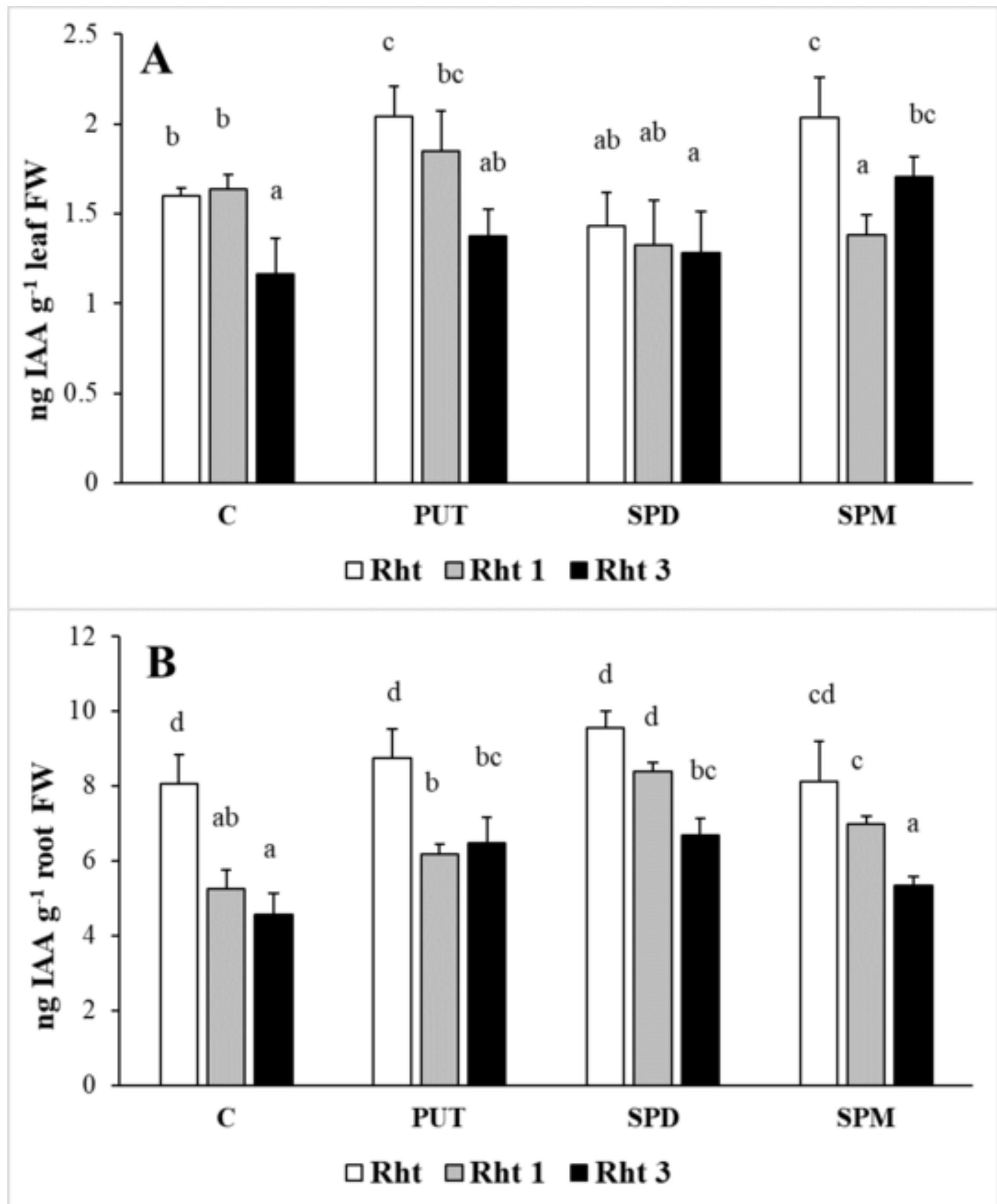

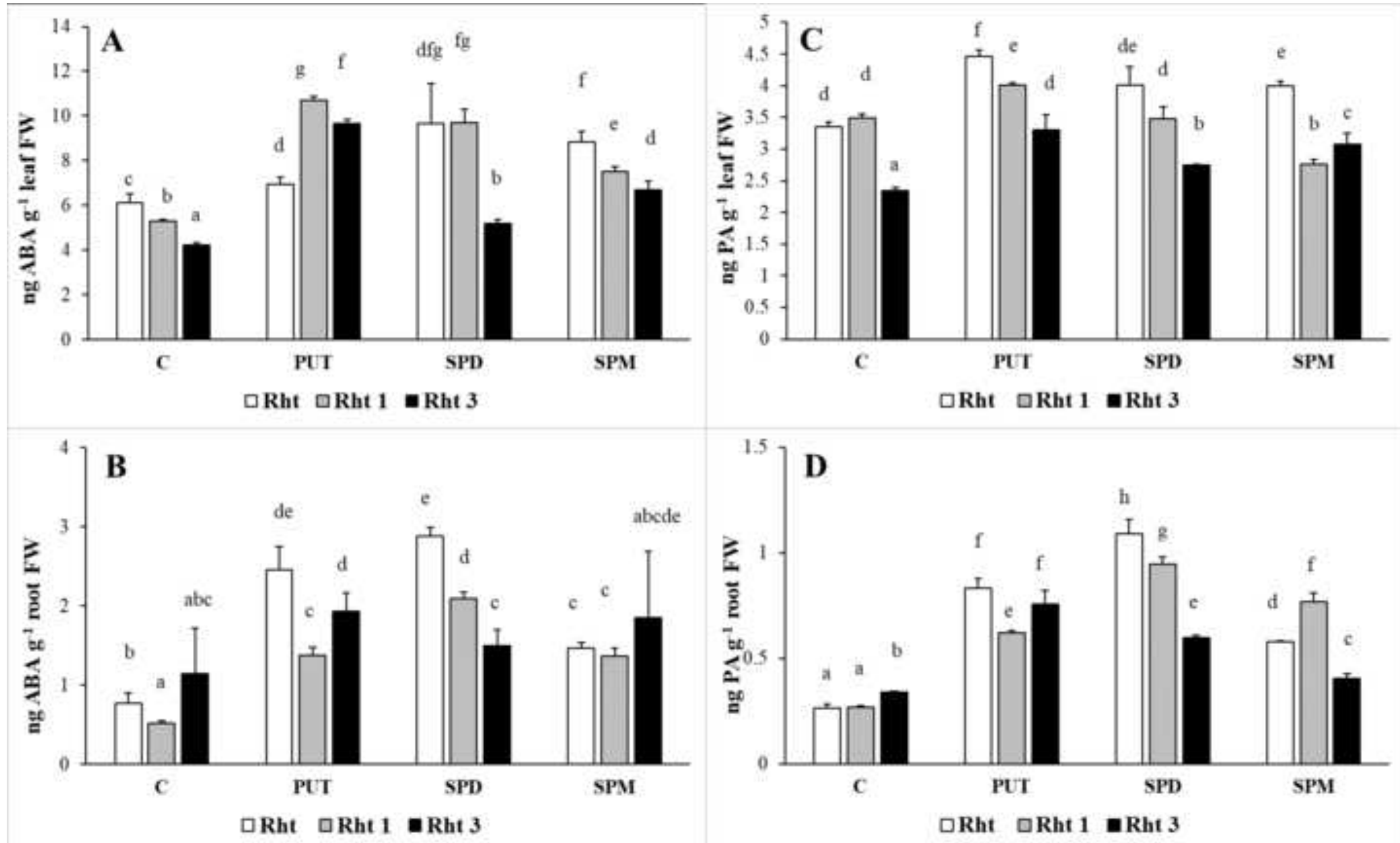


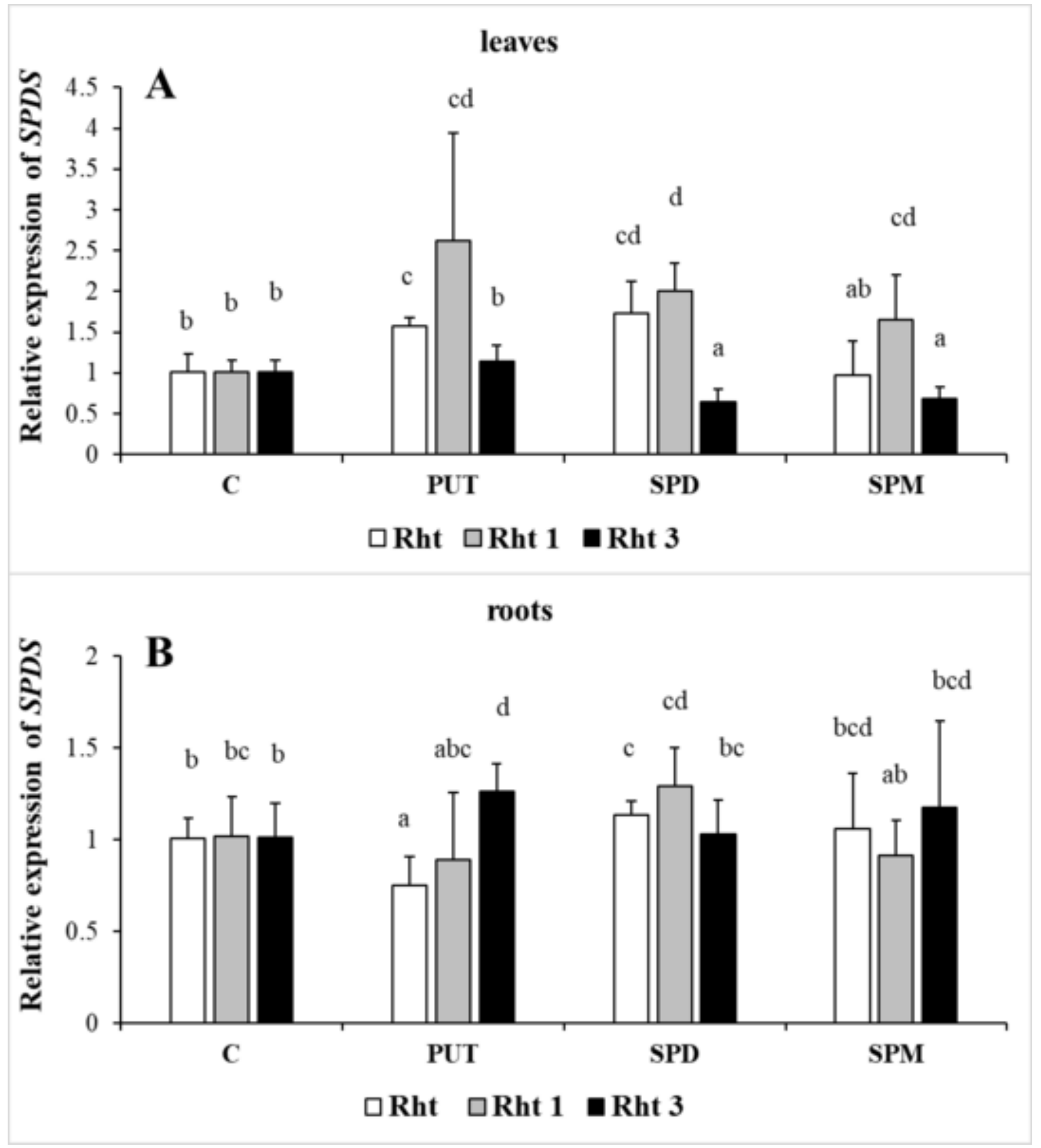




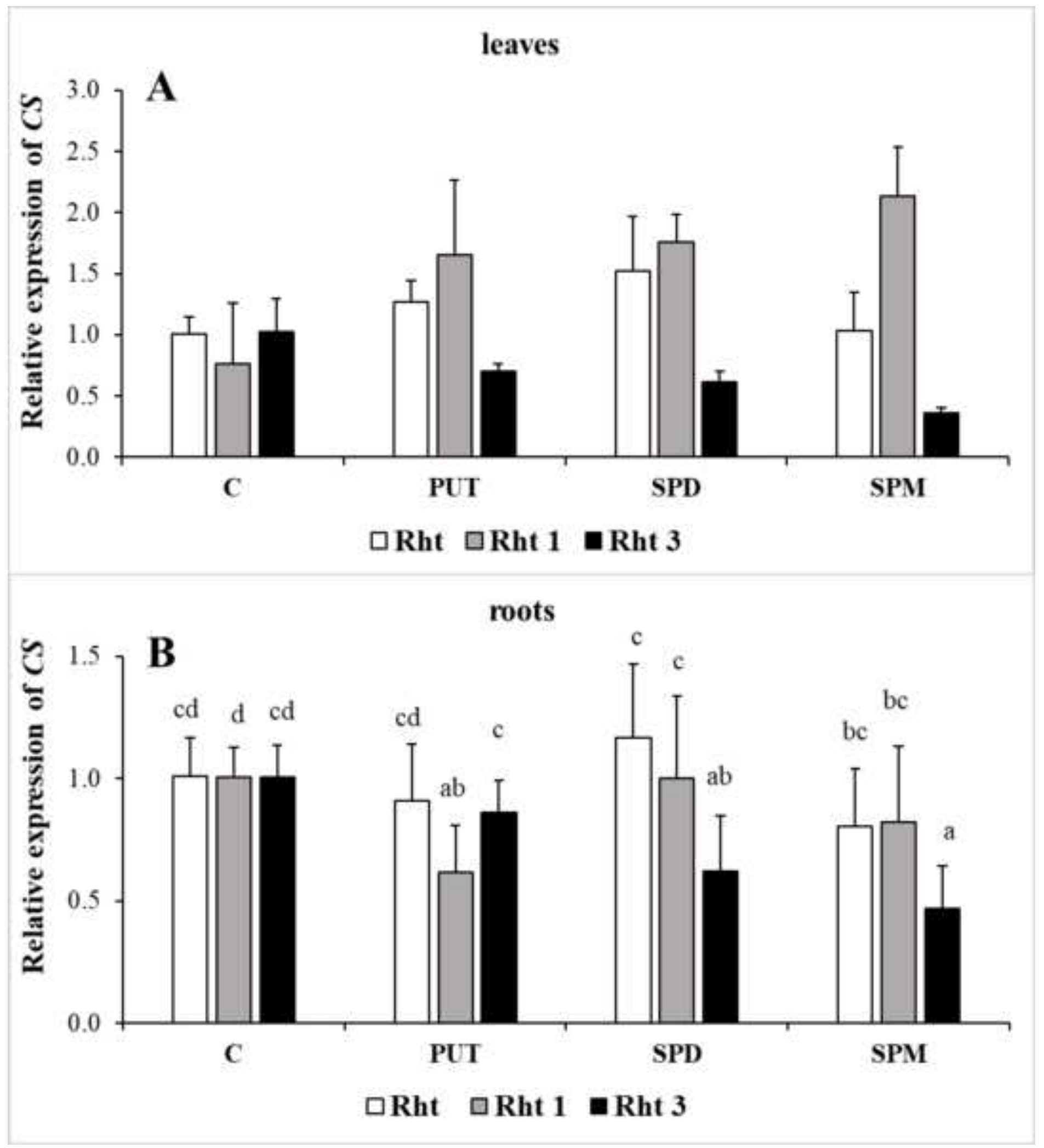




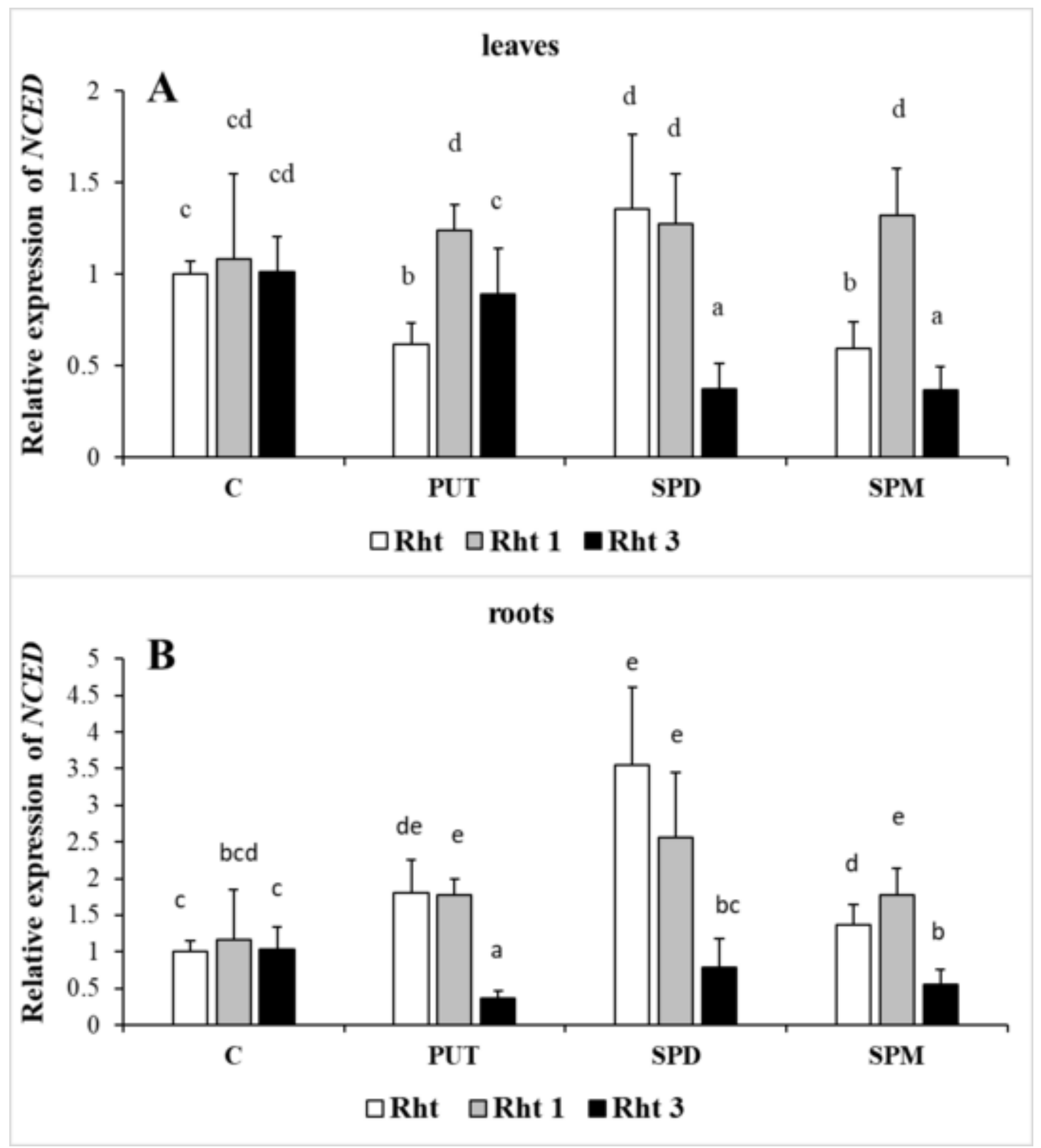

